TITLE:

\title{
Oxygen reduction on bimodal nanoporous palladium-copper catalyst synthesized using sacrificial nanoporous copper
}

\section{$\operatorname{AUTHOR}(\mathrm{S}):$}

Miyazawa, Naoki; Hakamada, Masataka; Sato, Yuto; Mabuchi, Mamoru

\section{CITATION:}

Miyazawa, Naoki ...[et al]. Oxygen reduction on bimodal nanoporous palladium-copper catalyst synthesized using sacrificial nanoporous copper. Journal of Materials Research 2019, 34: 2086-2094

ISSUE DATE:

2019-06

URL:

http://hdl.handle.net/2433/261781

\section{RIGHT:}

This is a post-peer-review, pre-copyedit version of an article published in Journal of Materials Research. The final authenticated version is available online at: http://dx.doi.org/10.1557/jmr.2019.154.; この論文は出版社版でありません 。引用の際には出版社版をご磪認じ利用ください。; This is not the published version. Please cite only the published version. 


\title{
Oxygen reduction on bimodal nanoporous palladium-copper catalyst synthesized using sacrificial nanoporous copper
}

\author{
Naoki Miyazawa, Masataka Hakamada*, Yuto Sato and Mamoru Mabuchi \\ Department of Energy Science and Technology, Graduate School of Energy Science, Kyoto University, \\ Yoshidahonmachi, Sakyo, 606-8501 Kyoto, Japan
}

* Corresponding author. E-mail: hakamada.masataka.3x@kyoto-u.ac.jp (M. Hakamada).

\begin{abstract}
Nanoporous copper (NP-Cu), as a sacrificial support, was used for the synthesis of bimodal nanoporous palladium-copper (BNP-PdCu) for oxygen reduction reaction (ORR) electrodes in fuel cells. The catalytic performance of BNP-PdCu in ORR per electrochemical surface area was enhanced by the dissolution and removal of supporting NP-Cu, which indicates that the intrinsic catalytic properties of palladium are improved by the proposed synthesis strategy including galvanic replacement of copper with palladium, following copper dissolution. $\mathrm{Cu}$ remained on $\mathrm{Pd}$ surfaces even after dissolution of $\mathrm{Cu}$. Additionally, significant local lattice contraction was observed at the ligament surface. First-principles calculations on the adsorbing oxygen species on Pd show that both lattice contraction and alloying with copper increase the binding energies of oxygen species to the Pd surface. The high ORR activity of the present BNP-PdCu is suggested to be mainly due to the Cu-ligand effect.
\end{abstract}

Keywords: Pd; nanostructure; surface reaction 


\section{Introduction}

Catalytic electrodes in fuel cells are typically made from platinum, which is rare in the earth's crust. The scarcity is the main reason for the high and fluctuating price of platinum and prevents the wide application of fuel cells. The performance of fuel cells is often governed by the oxygen-reduction reaction (ORR) at an air electrode. ${ }^{[1]}$ Thus, various studies on the optimization of catalytic platinum electrodes have been conducted..$^{[1-3]}$

Another effort is the substitution of platinum by other elements. Palladium is one possible element for the substitution because the electronic structure of palladium is similar to that of platinum, which is clearly understood from the periodic table. From the viewpoint of surface area, nanostructuring of palladium is a key strategy for the efficient production of the air electrode. However, it has been found that the catalytic properties of palladium for ORR are much lower than those of platinum. ${ }^{[4]}$ For this reason, many studies have been carried out to achieve a better catalytic performance of palladium than platinum by efforts such as nanoparticle formation ${ }^{[5]}$ and alloying. ${ }^{[6]}$

Nanoporous metal synthesis, by dealloying or selective dissolution of one element from a binary alloy, has been developed after a report in $2001^{[7]}$ and is now another technology for nanostructuring. Dealloying can create three-dimensional nanoporous structures in various metals, which generate pores and ligaments in the nanometer-size range. ${ }^{[8,9]}$ It is well known that nanoporous Raney copper can be synthesized by dealloying $\mathrm{Cu}-\mathrm{Al}$ alloys in alkaline solutions. ${ }^{[10]}$ Nanoporous copper $(\mathrm{NP}-\mathrm{Cu})$ can also be produced by dealloying ductile $\mathrm{Cu}-$ Mn alloys. ${ }^{[1-13]}$ Manganese is easy to dissolve even in neutral solution; ${ }^{[14]}$ thus the precursor $\mathrm{Cu}-\mathrm{Mn}$ alloys may be favorable for efficient production of NP-Cu.

Noble metals, including palladium, can be deposited in the form of a dense film or fine 
particles on copper by electroless plating or galvanic replacement. ${ }^{[15-17]}$ Thus, nanoporous palladium with a skeletal structure replicated from NP-Cu can be produced by electroless plating of palladium on NP-Cu. The supporting NP-Cu can be removed readily by $\mathrm{HNO}_{3}$ which dissolves copper selectively, and leaves bimodal nanoporous platinum with residual copper (BNP-PdCu) (Fig. 1). In addition, the distribution of lattice spacing from surface to core is significantly varied in nanostructured materials including nanoporous metals, ${ }^{[18,19]}$ causing peculiar surface chemistry. ${ }^{[18,20-22]}$ In this study, BNP-PdCu for ORR catalysts was fabricated by electroless plating of palladium on the sacrificial NP-Cu and subsequent dissolution of NP-Cu. We focus on high ORR activity per surface area of fabricated BNP$\mathrm{PdCu}$ catalysts, using first-principles calculations on the adsorption of oxygen species on palladium surfaces.

\section{Results}

STEM images (Fig. 2) indicated the bimodal structure of the BNP-PdCu after dissolution of copper. The nanoporous hollow structure with an average pore diameter of $23 \mathrm{~nm}$ (Fig. 2(a)), which is replicated from NP-Cu (Fig. 1(b)), was composed of finer Pd aggregates with 5-10-nm diameters (Fig. 2(b)), forming the bimodal nanoporous structure. STEM-EDXS revealed that $\mathrm{Cu}$ remained even after dissolution by $\mathrm{HNO}_{3}$, although $\mathrm{Cu}$ and $\mathrm{Pd}$ exhibited a homogeneous distribution without surface segregation (Fig. 2(c)). HR-TEM observation (Fig. 2(d)) showed significant local lattice contraction at ligament surfaces. The remaining $\mathrm{Cu}$ in the sample after dissolution by $\mathrm{HNO}_{3}$ was confirmed by EDXS (Fig. 3(a)), where the atomic ratio of $\mathrm{Cu} / \mathrm{Pd}$ was 0.25 before dissolution and 0.15 after dissolution. On the other hand, manganese was not detected by EDXS and ICP-AES in BNP-PdCu before and after the dissolution of copper. Thus, the contribution of manganese was eliminated in the following 
discussion on the catalytic properties of the BNP-PdCu samples.

XRD patterns of BNP-PdCu before and after copper dissolution are shown in Fig. 3(b). Before copper dissolution, the broad peaks for palladium were detected with minor peaks for metallic copper. The absence of copper peaks in the XRD pattern even before dissolution of copper suggested that a considerable amount of copper was removed the stage of the displacement deposition of palladium. Comparison of the present $\mathrm{Cu} / \mathrm{Pd}$ composition ratio with the case of $\mathrm{Cu} / \mathrm{Pt}^{[23]}$ also suggested the removal of copper during the displacement deposition of palladium. The broad peaks for palladium were detected whereas no copper was detected by XRD after dissolution by $\mathrm{HNO}_{3}$. Pd remained undissolved after immersion in $\mathrm{HNO}_{3}$ for removal of skeletal $\mathrm{Cu}$. An inspection of the XRD patterns showed no significant peak shift of Pd (Table I), compared with the case of $\mathrm{Cu} / \mathrm{Pt}^{[23]}$

CV curves for BNP-PdCu before and after copper dissolution (Fig. 4(a)) were typical for palladium ${ }^{[24-26]}$ with peaks for oxygen desorption. Copper dissolution by $\mathrm{HNO}_{3}$ caused no significant change in the redox process during CV scanning. On the other hand, no redox peaks from copper were detected. Considering that elemental mapping in TEM for BNPPdCu showed no clear segregation of palladium and copper (Fig. 2(c)), one can suggest that the change in the chemical state of surface $\mathrm{Cu}$ by alloying with $\mathrm{Pd}$ and/or that the surface coverage by $\mathrm{Cu}$ is not so high.

The ORR activity of the BNP-PdCu samples was examined by RDE (Fig. 4(b)). In the polarization curves, the current density at a high potential of $1.1 \mathrm{~V}$ was almost independent of the electrode rotation rate, which corresponded to the kinetic region of the ORR. As the potential was decreased from $1.1 \mathrm{~V}$, transitional regions from a kinetic- to a diffusion- 
controlled reaction rate were observed, with a lower current density at a higher electrode rotation rate. Below $0.4 \mathrm{~V}$, the current density was almost constant and a diffusion-controlled reaction occurred.

The specific activities of BNP-PdCu before and after dissolution of copper were 0.32 and $0.61 \mathrm{~mA} \mathrm{~cm}^{-2}$, respectively, according to the RDE results. These values were significantly higher than those of the conventional $\mathrm{Pd} / \mathrm{C}$ catalyst and comparable with the values reported recently for other nanostructured Pd-based alloys. ${ }^{[27-31]}$ On the other hand, the mass activity of BNP-PdCu before and after copper dissolution was 0.023 and $0.034 \mathrm{~A} \mathrm{mg}_{\mathrm{Pd}}{ }^{-1}$, respectively. The copper dissolution increased the specific activity of the BNP-PdCu. A higher activity per ECSA (not per mass or geometric area) for BNP-PdCu after copper dissolution meant that the copper dissolution enhanced the intrinsic ORR catalytic nature of the palladium.

\section{Discussion}

In the case of platinum, which has been examined intensively in previous studies, lattice straining affects the overall catalytic performance for ORR in platinum; ${ }^{[32-34]}$ lattice contraction is favorable for efficient ORR catalysis on platinum. ${ }^{[32]}$ However, it has been reported that both lattice contraction ${ }^{[35-37]}$ and expansion ${ }^{[27]}$ in palladium catalysts enhances the overall catalytic performance for ORR. XRD analyses revealed that the apparent lattice constants of palladium in BNP-PdCu are close to those for bulk palladium (Table I), which is in contrast with the case of BNP-Pt ${ }^{[23]}$. However, HR-TEM of BNP-PdCu showed significant local lattice contraction at ligament surfaces, as exemplified in Fig. 2(d). That is, the lattice spacing at the surface of ligaments is smaller than that in the bulk part of ligaments. This lattice disorder at the surface of nanoligaments is often observed in nanoporous metals and is attributed to the complex three-dimensional nanostructure with positive and negative 
curvatures. ${ }^{[18,19,22]}$ The present BNP-PdCu is replicated from NP-Cu; therefore, the lattice disorder is likely to be prominent, considering the increased complexity in the replicated BNP structure.

It is known that the binding of oxygen species to Pd surfaces is too strong and it is difficult to cause further reduction of the oxygen species to form water on Pd surfaces. ${ }^{[46,47]}$ Therefore, a weak oxygen binding is desirable to balance the rates of electron transfer/O-O bond breaking and removal of $\mathrm{O}$ species from Pd surfaces. ${ }^{[2]}$ As shown above, $\mathrm{Cu}$ remained on the BNP-PdCu surface even after dissolution by $\mathrm{HNO}_{3}$, in addition, a lattice disorder was generated at its surface. Therefore, it is suggested that the Cu-ligand effect and/or the strain effect led to the high ORR activity of BNP-PdCu. To obtain insights in the origins of the high ORR activity of $\mathrm{BNP}-\mathrm{PdCu}$, the binding energies of $\mathrm{O}$ and $\mathrm{O}_{2}$ to $\mathrm{Pd}$ and $\mathrm{PdCu}$ were calculated. The results are shown for Pd in Fig. 5 and for PdCu in Fig. 6. The most stable binding sites for $\mathrm{Pd}$ were the fcc for $\mathrm{O}$ and the $\mathrm{t}-\mathrm{f}-\mathrm{b}$ for $\mathrm{O}_{2}$, regardless of the strain. However, the most stable binding sites for PdCu were different from those for Pd. The most stable binding sites and binding energies are listed in Table II. Table II shows that the binding energies of the oxygen species are increased (negatively decreased) by the contraction strain for Pd, while the binding energies are decreased (negatively increased) by the expansion strain, which indicates that the contraction strain enhances the desorption of oxygen species on Pd although the expansion strain disturbs the desorption. Thus, the contraction strain leads to the enhanced ORR activity of Pd. In addition, Table II shows that the binding energies are increased by the addition of $\mathrm{Cu}$, regardless of the strain. This suggests that the ORR activity of $\mathrm{Pd}$ is enhanced owing to the Cu-ligand effect. The Cu-ligand effect can significantly enhance the ORR activity of Pd because the binding energies are largely increased by the addition of $\mathrm{Cu}$. 
The densities of states (DOS) for a palladium atom of the Pd (PdCu) surface binding to an oxygen atom are shown in Fig. S1 in Supplementary Material. The electronic states for Pd were hardly changed by the presence of strains, which corresponds to the result that the strain had little effect on the d-band center for Pd (Table II). However, the electronic states were changed by the presence of $\mathrm{Cu}$ (see Fig. S1(a) and (d)). Both the downshift and upshift of the d-band center were caused by the addition of $\mathrm{Cu}$ (Table II). Thus, the variation in binding energy by the addition of $\mathrm{Cu}$ cannot be explained only from the viewpoint of the d-band center. The charge density distribution between the palladium and oxygen atoms is shown in Fig. 7. The charge density between the palladium and oxygen atoms was lower for $\mathrm{PdCu}$ than for Pd. Therefore, it is proposed that the binding energy increased by the addition of $\mathrm{Cu}$ is related to the reduced charge density.

As shown above, the contraction strain and the addition of $\mathrm{Cu}$ enhance the ORR activity of Pd. Hence, the high ORR activity of BNP-PdCu may be related to both the strain effect and the Cu-ligand effect. The present experimental results showed that the ORR activity was enhanced by the dissolution of $\mathrm{Cu}$, although the contraction strain might be reduced and the amount of $\mathrm{Cu}$ on $\mathrm{Pd}$ was reduced by the dissolution. The Pd surface that is covered by $\mathrm{Cu}$ before the dissolution cannot provide the sites for ORR. In such a case, only the strain effect enhances the ORR activity because the Pd surface that is not covered by $\mathrm{Cu}$ provides the sites for ORR. After the dissolution, however, not only the strain effect but also the Culigand effect enhances the ORR activity because $\mathrm{Cu}$ remains on the Pd surface. It is therefore suggested that the high ORR activity of BNP-Pd mainly arises from the Cu-ligand effect.

\section{Conclusions}

Efficient ORR BNP-PdCu catalysts were fabricated by using NP-Cu as a sacrificial metallic 
support. $\mathrm{Cu}$ remained on $\mathrm{Pd}$ surfaces even after dissolution of $\mathrm{Cu}$. The high ORR activity of BNP-PdCu was suggested to mainly arise from the Cu-ligand effect.

\section{Experimental methods}

Copper-manganese alloy ingots with the composition of $\mathrm{Cu}_{0.3} \mathrm{Mn}_{0.7}$ were fabricated by the arc melting of pure copper and manganese (Nilaco, Tokyo, Japan) in an Ar atmosphere. After heating at $1123 \mathrm{~K}$ for $24 \mathrm{~h}$ in an Ar atmosphere, the button-shaped alloy ingot was waterquenched, ${ }^{[40]}$ followed by cold rolling to $0.2-\mathrm{mm}$ thickness.

Dealloying to fabricate NP-Cu was conducted by free corrosion of the rolled $\mathrm{Cu}_{0.3} \mathrm{Mn}_{0.7}$ sheet in $1 \mathrm{~mol} \mathrm{~L}^{-1} \mathrm{HCl}$ for $24 \mathrm{~h}$, where manganese was dissolved selectively and copper formed a nanoporous structure spontaneously (Fig. 1(b))..$^{[1-13]}$ After recovery by percolation and washing in pure water, the NP-Cu was pulverized manually in an agate bowl.

$\mathrm{NP}-\mathrm{Cu}(0.05 \mathrm{~g})$ was mixed with $5 \mathrm{wt} \%$ Nafion ethanolic solution $(1 \mathrm{~g})$ and of water $(5 \mathrm{~g})$. After homogenization in an ultrasonic bath, the suspension was fixed on a glassy carbon (GC) rotation disk electrode (RDE) with 5-mm diameter. The displacement deposition of palladium on the fixed NP-Cu was conducted by immersing the GC RDE in diluted $\mathrm{HCl}$ containing $0.1 \mathrm{~mol} \mathrm{~L}^{-1} \mathrm{PdCl}_{2}$ at $273 \mathrm{~K}$ for $1 \mathrm{~h}$ at $600 \mathrm{rpm} \cdot{ }^{[41]}$ Thus, the GC electrode included NP-Cu with a fine palladium deposition; the bimodal nanoporous structure of palladium supported on NP-Cu was expected to form already at this step (Fig. 1(a)). The GC electrode that included BNP-PdCu was immersed in $0.1 \mathrm{~mol} \mathrm{~L}^{-1} \mathrm{HNO}_{3}$ for $18 \mathrm{~h}$ to dissolve the supporting copper.

We conducted cyclic voltammetry $(\mathrm{CV})$ at room temperature by using the GC electrode loaded with BNP-PdCu as a working electrode. To evaluate the electrochemical surface area 
(ECSA) of the BNP-PdCu samples, $\mathrm{CV}$ was conducted in degassed $0.1 \mathrm{~mol} \mathrm{~L}^{-1} \mathrm{H}_{2} \mathrm{SO}_{4}$ with a scan rate of $10 \mathrm{mV} \mathrm{s}^{-1}$. A reversible hydrogen electrode (RHE) and Pt wire were used as a reference and counter electrode, respectively. For electrochemical cleaning, CV was repeated until a steady current-potential cyclic curve was attained. The charge $\left(Q_{0}\right)$ associated with the reduction of oxidized monolayer was calculated by using the cathodic peak between 0.6 and $0.8 \mathrm{~V}$ (vs. RHE), which was then converted to the ECSA $(A)$ of the sample: ${ }^{[42]}$

$$
A_{\text {sample }} / A_{\text {bulk }}=Q_{0, \text { sample }} / Q_{0, \text { bulk }}
$$

where the subscripts "sample" and "bulk" represent the BNP-PdCu and bulk palladium, respectively.

The working GC-RDE-loaded BNP-PdCu was rotated for ORR activity measurements during $\mathrm{CV}$ in an electrolyte of $\mathrm{O}_{2}$-saturated $0.1 \mathrm{~mol} \mathrm{~L}^{-1} \mathrm{H}_{2} \mathrm{SO}_{4}$ with a scan rate of $10 \mathrm{mV}$ $\mathrm{s}^{-1}$. The kinetically-controlled current $i_{\mathrm{K}}$, which is an index of the ORR activity of the BNP$\mathrm{PdCu}$, was calculated according to:

$$
1 / i=1 / i_{\mathrm{K}}+1 / B \omega^{1 / 2}
$$

where $i$ is the measured current; $B$ is a constant and $\omega$ is the RDE rotation speed. $i_{\mathrm{K}}$ was derived from the intersection at $\omega^{-1 / 2}=0$ by the Koutechy-Levich plot of $i^{-1}$ (at $0.70 \mathrm{~V}$ vs. RHE) against $\omega^{-1 / 2} \cdot{ }^{[43]}$

Substances on the GC RDE were collected for SEM, scanning transmission electron microscopy (STEM) and high-resolution transmission electron microscopy (HR-TEM). Energy-dispersive X-ray spectroscopy (EDXS) was used for elemental analyses in the microscopic observations. X-ray diffraction (XRD) patterns of the samples were collected under a parallel-beam configuration. The concentrations of palladium and other elements in 
the samples were determined by inductively-coupled plasma atomic emission spectroscopy (ICP-AES) after dissolving the samples in $20 \mathrm{~mL}$ of nitrohydrochloric acid.

\section{Calculation methods}

First-principles calculations on the adsorption of $\mathrm{O}$ and $\mathrm{O}_{2}$ on (111) $\mathrm{Pd}$ and $\mathrm{PdCu}$ surfaces were carried out to understand the origins for the catalytic activity of BNP-PdCu. The firstprinciples calculations were performed within the framework of density functional theory ${ }^{[44,45]}$ as implemented in the CASTEP code. ${ }^{[46]}$ The plane-wave basis set was used to calculate the electronic properties, and the generalized gradient approximation of the Perdew-Burke-Ernzerhof ${ }^{[47]}$ functional was used for the exchange-correlation potential for the structure optimizations. Ultrasoft pseudopotentials ${ }^{[48]}$ were used for all the elements in the calculations. We applied cutoff energies of $400 \mathrm{eV}$. The Brillouin zone was sampled using $5 \times 5 \times 1$ Monkhorst-Pack k-point meshes. ${ }^{[49]}$ Periodic boundary conditions were applied in the $\mathrm{x}, \mathrm{y}$ and $\mathrm{z}$ directions.

Atomic models are shown in Fig. S2 in Supplementary Material. The rectangular cell consisted of 4 layers of the (111) plane of Pd with a vacuum gap of $15 \AA$ between repeated slabs (Fig. S2(a)). The PdCu model was constructed by substituting one Pd atom at each layer except the top lay with one $\mathrm{Cu}$ atom to avoid direct reaction of a $\mathrm{Cu}$ atom with an oxygen atom (Fig. S2(b)). A 2\% tensile and compressive strain was applied parallel to the exposed surface to identify the strain effects. All cells were constructed from $2 \times 2$ surface unit cells. The top three layers were relaxed while the bottom layer was frozen during geometry optimization calculations. The binding energy of an oxygen species to a substrate $\left(E_{\mathrm{b}}\right)$ can be given by:

$$
E_{\mathrm{b}}=E_{\text {substrate+oxygen }}-E_{\text {substrate }}-E_{\text {oxygen }}
$$


where $E_{\text {substrate+oxygen }}$ is the internal energy of an oxygen species-binding substrate, $E_{\text {substrate }}$ is the internal energy of a substrate and $E_{\text {oxygen }}$ is the internal energy of an oxygen species. The most stable binding site of an oxygen species was defined as the site where the binding energy was the lowest among the various binding sites shown in Fig. S2, based on a previous study. ${ }^{[0]}$

\section{Acknowledgments}

TEM and STEM observations were conducted at the Kyoto University Nano Technology Hub in the "Nanotechnology Platform Project" sponsored by the Ministry of Education, Culture, Sports, Science and Technology (MEXT), Japan. Computation time for firstprinciples calculations was provided by the SuperComputer System, Institute for Chemical Research, Kyoto University. M. H. acknowledges financial support by JGC-S Scholarship Foundation.

\section{Supplementary Material}

To view supplementary material for this article, please visit [URL to be provided].

\section{References}

[1] I. E. L. Stephens, A. S. Bondarenko, U. Grønbjerg, J. Rossemeisl, and I. Chorkendorff: Understanding the electrocatalysis of oxygen reduction on platinum and its alloys. Energy Environ. Sci. 5, 6744-6762 (2012).

[2] K. Wikander, H. Ekström, A. E. C. Palmqvist, and G. Lindbergh: On the influence of Pt particle size on the PEMFC cathode performance. Electrochem. Acta 52, 6848-6855 (2007).

[3] R. Chattot, O. L. Bacq, V. Beermann, S. Kühl, J. Herranz, S. Henning, L. Kühn, T. Asset, 
L. Guétaz, G. Renou, J. Drnec, P. Bordet, A. Pasturel, A. Eychmüller, T. J. Schmidt, P. Strasser, L. Dubau, and F. Maillard: Surface distortion as a unifying concept and descriptor in oxygen reduction reaction electrocatalysis. Nat. Mater. 17, 827-833 (2018).

[4] D. Jung, S. Beak, K. S. Nahm, and P. Kim: Enhancement of oxygen reduction activity by sequential impregnation of Pt and Pd on carbon support. Korean J. Chem. Eng. 27, 1689-1694 (2010).

[5] S. Liu, X. Mu, H. Duan, C. Chen, and H. Zhang: Pd nanoparticle assemblies as efficient catalysts for the hydrogen evolution and oxygen reduction reactions. Eur. J. Inorg. Chem. 2017, $535-539$ (2017).

[6] M. Neergat, V. Gunasekar, and R. Rahul: Carbon-supported Pd-Fe electrocatalysts for oxygen reduction reaction (ORR) and their methanol tolerance. J. Electroanal. Chem. 658, 2532 (2011).

[7] J. Erlebacher, M. J. Aziz, A. Karma, N. Dimitrov, and K. Sieradzki: Evolution of nanoporosity in dealloying. Nature 410, 450-453 (2001).

[8] A. J. Forty: Corrosion micromorphology of noble metal alloys and depletion gilding. Nature 282, 597-598 (1979).

[9] D. V. Pugh, A. Dursun, and S. G. Corcoran: Formation of nanoporous platinum by selective dissolution of $\mathrm{Cu}$ from $\mathrm{Cu}_{0.75} \mathrm{Pt}_{0.25}$. J. Mater. Res. 18, 216-221 (2003).

[10] X. Kong, C. Ma, J. Zhang, J. Sun, J. Chen, and K. Liu: Effect of leaching temperature on structure and performance of Raney $\mathrm{Cu}$ catalysts for hydrogenation of dimethyl oxalate, Appl. Catal. A-Gen. 509, 153-160 (2016). 
[11] D. S. Keir and M. J. Pryor: The dealloying of copper-manganese alloys. J. Electrochem. Soc. $127,2138-2144(1980)$.

[12] U.-S. Min and J. C. M. Li: The microstructure and dealloying kinetics of a Cu-Mn alloy. J. Mater. Res. 9, 2878-2883 (1994).

[13] J. R. Hayes, A. M. Hodge, J. Biener, A. V. Hamza, and K. Sieradzki: Monolithic nanoporous copper by dealloying Mn-Cu. J. Mater. Res. 21, 2611- 2616 (2006).

[14] M. Hakamada and M. Mabuchi: Preparation of nanoporous Ni and Ni-Cu by dealloying of rolled Ni-Mn and Ni-Cu-Mn alloys. J. Alloy. Compd. 485, 583-587 (2009).

[15] A. Liu, H. Geng, C. Xu, and H. Qiu: A three-dimensional hierarchical nanoporous PdCu alloy for enhanced electrocatalysis and biosensing. Anal. Chem. Acta 703, 172-178 (2011).

[16] B. Rezaei, E. Havakeshian, and A. A. Ensafi: Fabrication of a porous Pd film on nanoporous stainless steelusing galvanic replacement as a novel electrocatalyst/electrode design for glycerol oxidation. Electrochem. Acta 136, 89-96 (2014).

[17] J.-B. Raoof, S. R. Hosseini, R. Ojani, and S. Aghajani: Fabrication of bimetallic Cu/Pd particlesmodified carbon nanotube paste electrode and its use towards formaldehyde electrooxidation. J. Mol. Liq. 204, 106-111 (2015).

[18] M. Hakamada, H. Nakano, T. Furukawa, M. Takahashi, and M. Mabuchi: Hydrogen storage properties of nanoporous palladium fabricated by dealloying. J. Phys. Chem. C 114, 868-873 (2010).

[19] C. Mahr, K. Müller-Caspary, M. Graf, A. Lackmann, T. Grieb, M. Schowalter, F. F. Krause, T. Mehrtens, A. Wittstock, J. Weissmüller, and A. Rosenauer: Measurement of local crystal 
lattice strain variations in dealloyed nanoporous gold. Mater. Res. Lett. 6, 84-92 (2018).

[20] M. Hakamada, F. Hirashima, and M. Mabuchi: Catalytic decoloration of methyl orange solution by nanoporous metals. Catal. Sci. Technol. 2, 1814-1817 (2012).

[21] M. Miyazawa, M. Hakamada, and M. Mabuchi: Antimicrobial mechanisms due to hyperpolarization induced by nanoporous Au. Sci. Rep. 8, 3870 (2018).

[22] T. Fujita, P. Guan, K. McKeena, X. Y. Lang, A. Hirata, L. Zhang, T. Tokunaga, S. Arai, Y. Yamamoto, N. Tanaka, Y. Ishikawa, N. Asao, Y. Yamamoto, J. Erlebacher, and M. W. Chen: Atomic origins of the high catalytic activity of nanoporous gold. Nat. Mater. 11, 775-780 (2012).

[23] M. Hakamada, Y. Sato, and M. Mabuchi: Bimodal nanoporous platinum on sacrificial nanoporous copper for catalysis of the oxygen-reduction reaction. MRS Commun. 9, 292297 (2019).

[24] W. Xiao, M. A. L. Cordeiro, M. Gong, L. Han, J. Wang, C. Bian, J. Zhu, H. L. Xin, and D. Wang: Optimizing the ORR activity of Pd based nanocatalysts by tuning their strain and particle size. J. Mater. Chem. A 5, 9867-9872 (2017).

[25] R. Rahul, R. K. Singh, B. Bera, R. Devivaraprasad, and M. Neergat: The role of surface oxygenated-species and adsorbed hydrogen in the oxygen reduction reaction (ORR) mechanism and product selectivity on Pd-based catalysts in acid media. Phys. Chem. Chem. Phys. 17, 15146-15155 (2015).

[26] Y. H. Xue, L. Zhang, W. J. Zhou and S. H. Chan. Int. J. Hydrogen Energy 39, 8449-8456 (2014). 
[27] M. Wang, X. Qin, K. Jiang, Y. Dong, M. Shao, and W.-B. Cai: Electrocatalytic activities of oxygen reduction reaction on $\mathrm{Pd} / \mathrm{C}$ and $\mathrm{Pd}-\mathrm{B} / \mathrm{C}$ catalysts. J. Phys. Chem. C 121, 34163423 (2017).

[28] D. Park, M. S. Ahmed, and S. Jeon: Covalent functionalization of graphene with 1,5diaminonaphthalene and ultrasmall palladium nanoparticles for electrocatalytic oxygen reduction. Int. J. Hydrogen Energy 42, 2061-2070 (2017).

[29] S. Salomé, A. M. Ferraria, A. M. Botelho do Rego, F. Alcaide, O. Savadogo, and R. Rego: Enhanced activity and durability of novel activated carbon-supported PdSn heat-treated cathode catalyst for polymer electrolyte fuel cells. Electrochem. Acta 192, 268-282 (2016)

[30] Y. Holade, C. Canaff, S. Poulin, T. W. Napporn, K. Servat, and K. B. Kokoh: High impact of the reducing agent on palladium nanomaterials: new insights from X-ray photoelectron spectroscopy and oxygen reduction reaction. RSC Adv. 6, 12627-12637 (2016).

[31] J. Begum, M. S. Ahmed, S. Cho, and S. Jeon: Freestanding palladium nanonetworks electrocatalyst for oxygen reduction reaction in fuel cells. Int. J. Hydrogen Energy 43, 229-238 (2018).

[32] P. Strasser, S. Koh, T. Anniyev, J. Greeley, K. More, G. Yu, Z. Liu, S. Kaya, D. Nordlund, H. Ogasawara, M. F. Toney, and A. Nilsson: Lattice-strain control of the activity in dealloyed core-shell fuel cell catalysts. Nat. Chem. 2, 454-460 (2010).

[33] F. M. F. Rhen and C. McKeown: Enhanced methanol oxidation on strained Pt films. J. Phys. Chem. C 121, 2556-2562 (2017).

[34] H. A. Gasteiger, S. S. Kocha, B. Sompalli, and F. T. Wagner: Activity benchmarks and 
requirements for Pt, Pt-alloy, and non-Pt oxygen reduction catalysts for PEMFCs. Appl. Catal. B-Environ. 56, 9-35 (2005).

[35] G. Jiang, H. Zhu, X. Zhang, B. Shen, L. Wu, S. Zhang, G. Lu, Z. Wu, and S. Sun: Core/shell face-centered tetragonal FePd/Pd nanoparticles as an efficient non-Pt catalyst for the oxygen reduction reaction. ACS Nano 9, 11014-11022 (2015).

[36] H. Zhang, Q. Hao, H. Geng, and C. Xu: Nanoporous PdCu alloys as highly active and methanol-tolerant oxygen reduction electrocatalysts. Int. J. Hydrogen Energy 38, 10029-10038 (2013).

[37] L. Liu, G. Samjeske, S. Nagamatsu, O. Sekizawa, K. Nagasawa, S. Takao, Y. Imaizumi, T. Yamamoto, T. Uruga, and Y. Iwasawa. Dependences of the oxygen reduction reaction activity of $\mathrm{Pd}-\mathrm{Co} / \mathrm{C}$ and $\mathrm{Pd}-\mathrm{Ni} / \mathrm{C}$ alloy electrocatalysts on the nanoparticle size and lattice constant. Top. Catal. 57, 595-606 (2014).

[38] M. Shao: Palladium-based electrocatalysts for hydrogen oxidation and oxygen reduction reactions. J. Power Sources 196, 2433-2444 (2011).

[39] M. H. Shao, T. Huang, P. Liu, J. Zhang, K. Sasaki, M. B. Vukmirovic, and R. R. Adzic: Palladium monolayer and palladium alloy electrocatalysts for oxygen reduction. Langmuir 22, $10409-10415$ (2006).

[40] H. Okamoto: Cu-Mn (Copper-Manganese). J. Phase Equilib. 19, 180 (1998).

[41] E. J. Coleman and A. C. Co: Galvanic displacement of Pt on nanoporous copper: An alternative synthetic route for obtaining robust and reliable oxygen reduction activity. J. Catal. 316, 191-200 (2014). 
[42] S. Trasatti and O. A. Petrii: Real surface area measurements in electrochemistry. J. Electroanal. Chem. 327, 353-376 (1992).

[43] L.-L. He, P. Song, A.-J. Wang, J.-N. Zheng, L.-P. Mei, and J.-J. Feng: A general strategy for the facile synthesis of $\mathrm{AuM}(\mathrm{M}=\mathrm{Pt} / \mathrm{Pd})$ alloyed flowerlike-assembly nanochains for enhanced oxygen reduction reaction. J. Mater. Chem. A 3, 5352-5359 (2015).

[44] P. Hohenberg and W. Kohn: Inhomogeneous electron gas, Phys. Rev. 136, B864-B871 (1964).

[45] W. Kohn and L. J. Sham: Self-Consistent equations including exchange and correlation effects, Phys. Rev. 140, A1133-A1138 (1965).

[46] M. C. Payne, M. P. Teter, D. C. Allan, T. A. Arias, and J. D. Joannopoulos: Iterative minimization techniques for ab initio total-energy calculations: molecular dynamics and conjugate gradients, Rev. Mod. Phys. 64, 1045-1097 (1992).

[47] J. P. Perdew, K. Burke, and M. Ernzerhof: Generalized gradient approximation made simple, Phys. Rev. Lett. 77, 3865-3867 (1996).

[48] D. Vanderbilt: Soft self-consistent pseudopotentials in a generalized eigenvalue formation, Phys. Rev. B 41, 7892-7895 (1990).

[49] H. J. Monkhorst and J. D. Pack: Special points for Brillouin-zone integrations, Phys. Rev. B 13, 5188-5192 (1976).

[50] Y. Xu, A. V. Ruban, and M. Mavrikakis: Adsorption and dissociation of $\mathrm{O}_{2}$ on Pt-Co and Pt-Fe alloys. J. Am. Chem Soc. 126, 4717-4725 (2004). 


\section{Tables}

Table I. Lattice constants of palladium in bimodal nanoporous palladium-copper.

\begin{tabular}{ccc}
\hline & \multicolumn{1}{c}{ Lattice constant $a(\mathrm{~nm})$ and change from that in bulk palladium } \\
Plane index & $\left(a_{\text {bulk Pd }}=3.890 \mathrm{~nm}\right)$ \\
& Before Cu dissolution & After Cu dissolution \\
\hline 111 & $3.880(-0.27 \%)$ & $3.879(-0.29 \%)$ \\
200 & $3.888(-0.05 \%)$ & $3.885(-0.13 \%)$ \\
220 & $3.874(-0.42 \%)$ & $3.879(-0.29 \%)$ \\
311 & $3.882(-0.21 \%)$ & $3.889(-0.04 \%)$ \\
\hline Average & $3.881(-0.24 \%)$ & $3.883(-0.19 \%)$ \\
\hline
\end{tabular}


Table II. Most stable binding sites, their binding energies and d-band centers by firstprinciples calculations on binding of $\mathrm{O}$ and $\mathrm{O}_{2}$ to (111) $\mathrm{Pd}$ and $\mathrm{PdCu}$ surfaces.

\begin{tabular}{|c|c|c|c|c|c|}
\hline \multicolumn{2}{|c|}{ System } & Strain & Stable binding site & $\begin{array}{c}\text { Binding energy } \\
(\mathrm{eV})\end{array}$ & $\begin{array}{c}\text { d-band center } \\
(\mathrm{eV})\end{array}$ \\
\hline \multirow[t]{6}{*}{$\mathrm{Pd}$} & $\mathrm{O}$ & $0 \%$ & fcc & -5.05 & -1.01 \\
\hline & & $+2 \%$ & fcc & -5.10 & -1.01 \\
\hline & & $-2 \%$ & fcc & -4.99 & -1.01 \\
\hline & $\mathrm{O}_{2}$ & $0 \%$ & $t-f-b$ & -1.44 & -0.67 \\
\hline & & $+2 \%$ & $t-f-b$ & -1.47 & -0.59 \\
\hline & & $-2 \%$ & $t-f-b$ & -1.39 & -0.68 \\
\hline \multirow[t]{6}{*}{$\mathrm{PdCu}$} & $\mathrm{O}$ & $0 \%$ & top1 & -4.74 & -1.10 \\
\hline & & $+2 \%$ & hсp3 & -4.93 & -0.99 \\
\hline & & $-2 \%$ & top3 & -4.79 & -0.97 \\
\hline & $\mathrm{O}_{2}$ & $0 \%$ & t-f-bc & -1.27 & -0.64 \\
\hline & & $+2 \%$ & $t-f-b c$ & -1.43 & -0.61 \\
\hline & & $-2 \%$ & $t-b-t b$ & -1.29 & -0.62 \\
\hline
\end{tabular}




\section{Figure captions}

Figure 1. (Color online) (a) Schematic illustration of synthesis of bimodal nanoporous PdCu using nanoporous copper as a sacrificial support. (b) Scanning electron microscopy image of nanoporous copper fabricated by dealloying of $\mathrm{Cu}-\mathrm{Mn}$ alloy.

Figure 2. (Color online) Scanning transmission electron microscopy images of bimodal nanoporous PdCu. (a), (b) and left panel in (c) are high-angle annular dark-field images, and the center and right panels in (c) show the elemental mapping by energy-dispersive X-ray spectroscopy. Arrows in (a) shows diameters of replicated pores from nanoporous copper. (d) High-resolution transmission electron microscopy image of bimodal nanoporous PdCu, showing surface lattice contraction.

Figure 3. (Color online) (a) Energy-dispersive X-ray spectroscopy results and (b) X-ray diffraction patterns of bimodal nanoporous $\mathrm{PdCu}$ before and after copper dissolution.

Figure 4. (Color online) (a) Cyclic voltammetry curves for bimodal nanoporous PdCu before and after copper dissolution. The scan rate was $10 \mathrm{mV} \mathrm{s}^{-1}$ and the electrolyte was $0.1 \mathrm{~mol}$ $\mathrm{L}^{-1} \mathrm{H}_{2} \mathrm{SO}_{4}$. (b) Polarization curves for rotation disk electrodes that load bimodal nanoporous PdCu before and after copper dissolution. The scan rate was $10 \mathrm{mV} \mathrm{s}^{-1}$ and the electrolyte was $0.1 \mathrm{~mol} \mathrm{~L}^{-1} \mathrm{H}_{2} \mathrm{SO}_{4}$.

Figure 5. (Color online) Binding energies of $\mathrm{O}$ and $\mathrm{O}_{2}$ to $\mathrm{Pd}$ surface, (a) $\mathrm{O}$ binding energy at $0 \%$ strain for fcc, hcp and top sites, (b) $\mathrm{O}_{2}$ binding energy at $0 \%$ strain for $\mathrm{t}-\mathrm{f}-\mathrm{b}, \mathrm{t}-\mathrm{h}-\mathrm{b}$ and t-b-t sites, (c) O binding energy at 2\% contraction strain for fcc, hcp and top sites, (d) $\mathrm{O}_{2}$ binding energy at $2 \%$ contraction strain for $\mathrm{t}-\mathrm{f}-\mathrm{b}, \mathrm{t}-\mathrm{h}-\mathrm{b}$ and $\mathrm{t}-\mathrm{b}-\mathrm{t}$ sites, (e) $\mathrm{O}$ binding energy at $2 \%$ expansion strain for fcc, hcp and top sites, (f) $\mathrm{O}_{2}$ binding energy at $2 \%$ expansion 
strain for $\mathrm{t}-\mathrm{f}-\mathrm{b}, \mathrm{t}-\mathrm{h}-\mathrm{b}$ and $\mathrm{t}-\mathrm{b}-\mathrm{t}$ sites.

Figure 6. (Color online) Binding energies of $\mathrm{O}$ and $\mathrm{O}_{2}$ to $\mathrm{PdCu}$ surface, (a) $\mathrm{O}$ binding energy at $0 \%$ strain for fcc, hep and top sites, (b) $\mathrm{O}_{2}$ binding energy at $0 \%$ strain for $\mathrm{t}-\mathrm{f}-\mathrm{b}, \mathrm{t}-\mathrm{h}-\mathrm{b}$ and t-b-t sites, (c) $\mathrm{O}$ binding energy at 2\% contraction strain for fcc, hcp and top sites, (d) $\mathrm{O}_{2}$ binding energy at $2 \%$ contraction strain for $\mathrm{t}-\mathrm{f}-\mathrm{b}, \mathrm{t}-\mathrm{h}-\mathrm{b}$ and $\mathrm{t}-\mathrm{b}-\mathrm{t}$ sites, (e) O binding energy at $2 \%$ expansion strain for fcc, hcp and top sites, (f) $\mathrm{O}_{2}$ binding energy at $2 \%$ expansion strain for $\mathrm{t}-\mathrm{f}-\mathrm{b}, \mathrm{t}-\mathrm{h}-\mathrm{b}$ and $\mathrm{t}-\mathrm{b}-\mathrm{t}$ sites.

Figure 7. (Color online) Charge density distribution between palladium and oxygen atoms, (a) Pd surface with 0\% strain, (b) Pd surface with 2\% contraction strain and (c) PdCu surface with $0 \%$ strain. 
(a)

1. Nanoporous $\mathrm{Cu}$

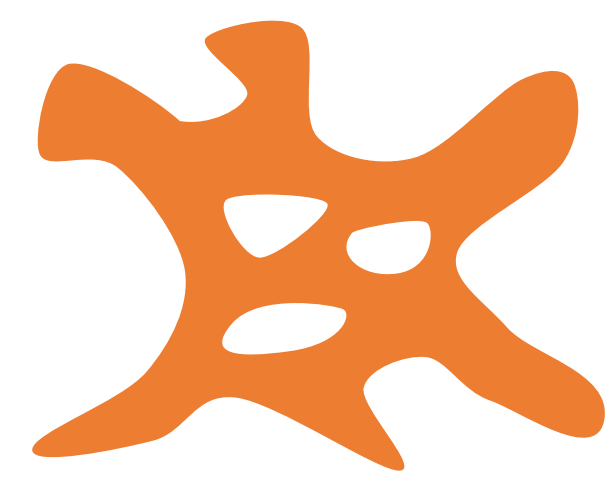

2. Galvanic replacement by $\mathbf{P d}$
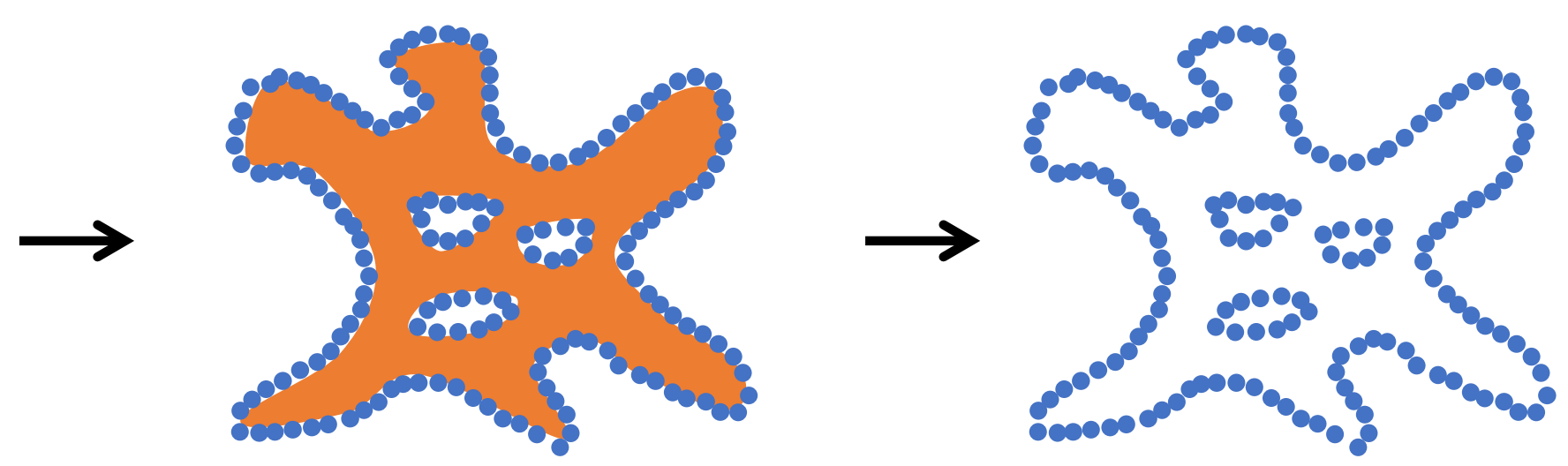

3. Cu dissolution

(b)

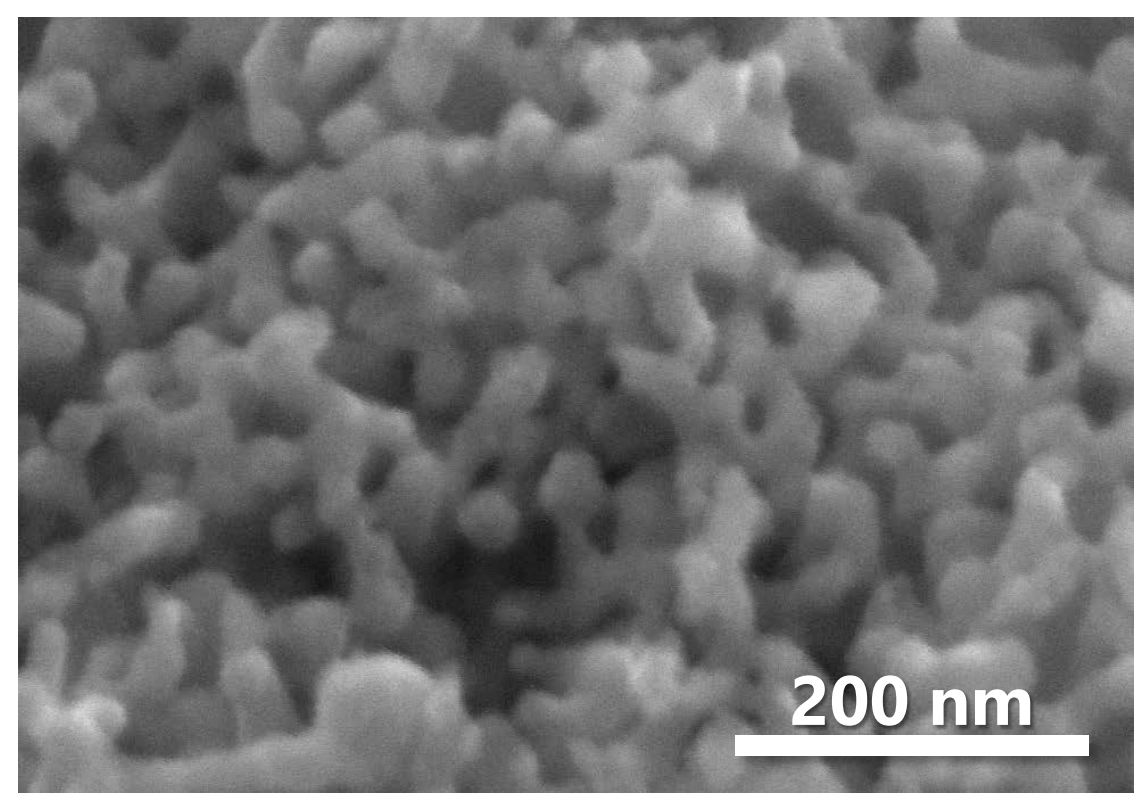


(a)

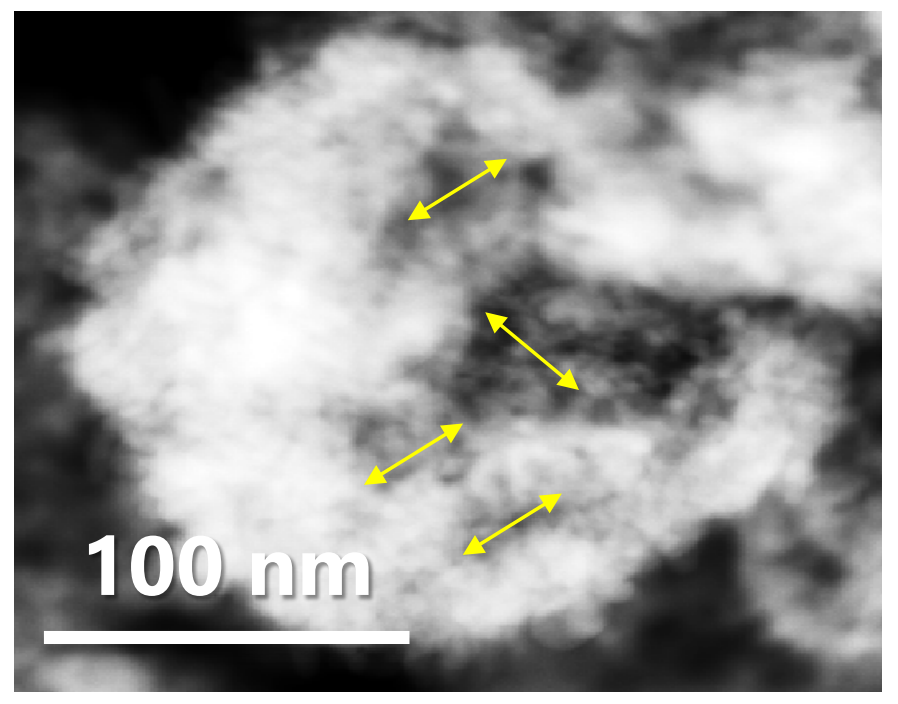

(c)
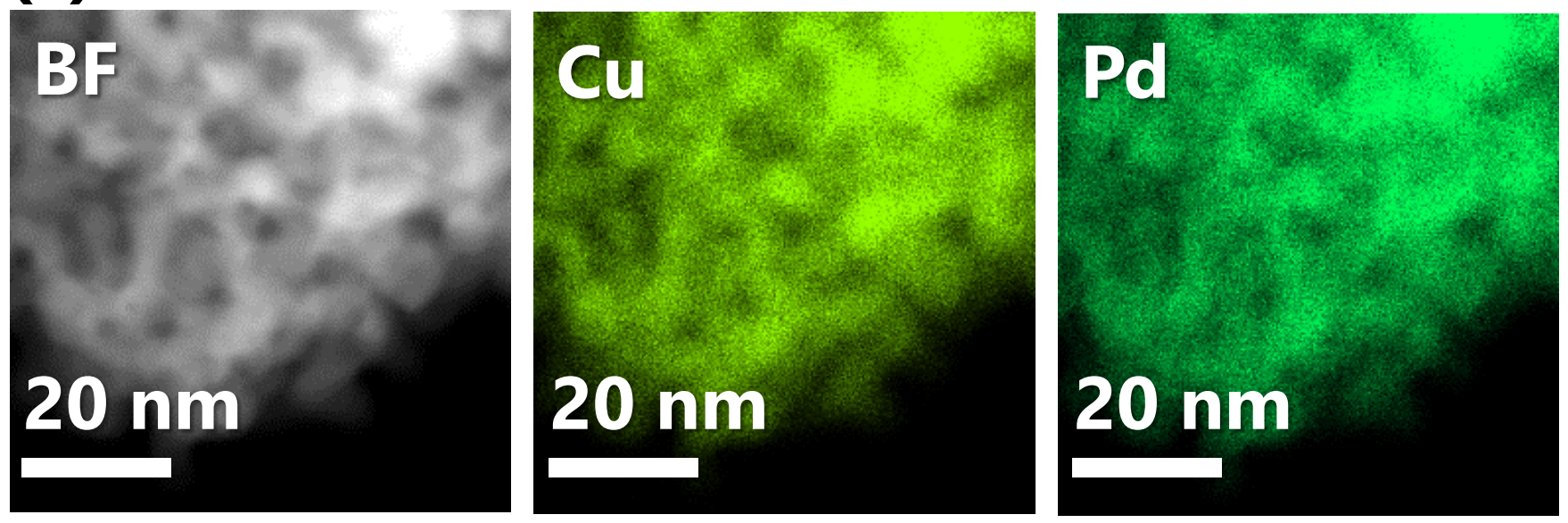

(b)

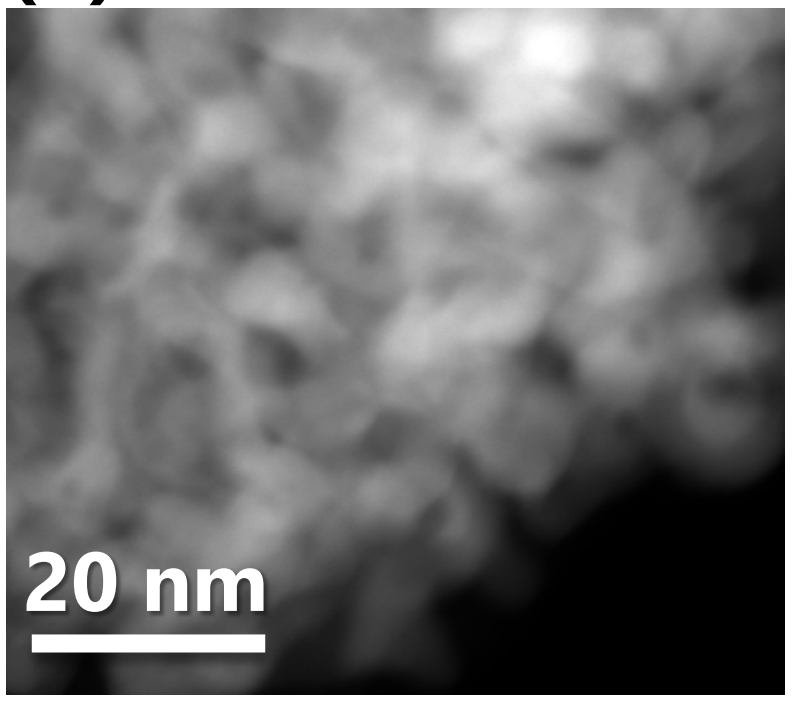

(d)

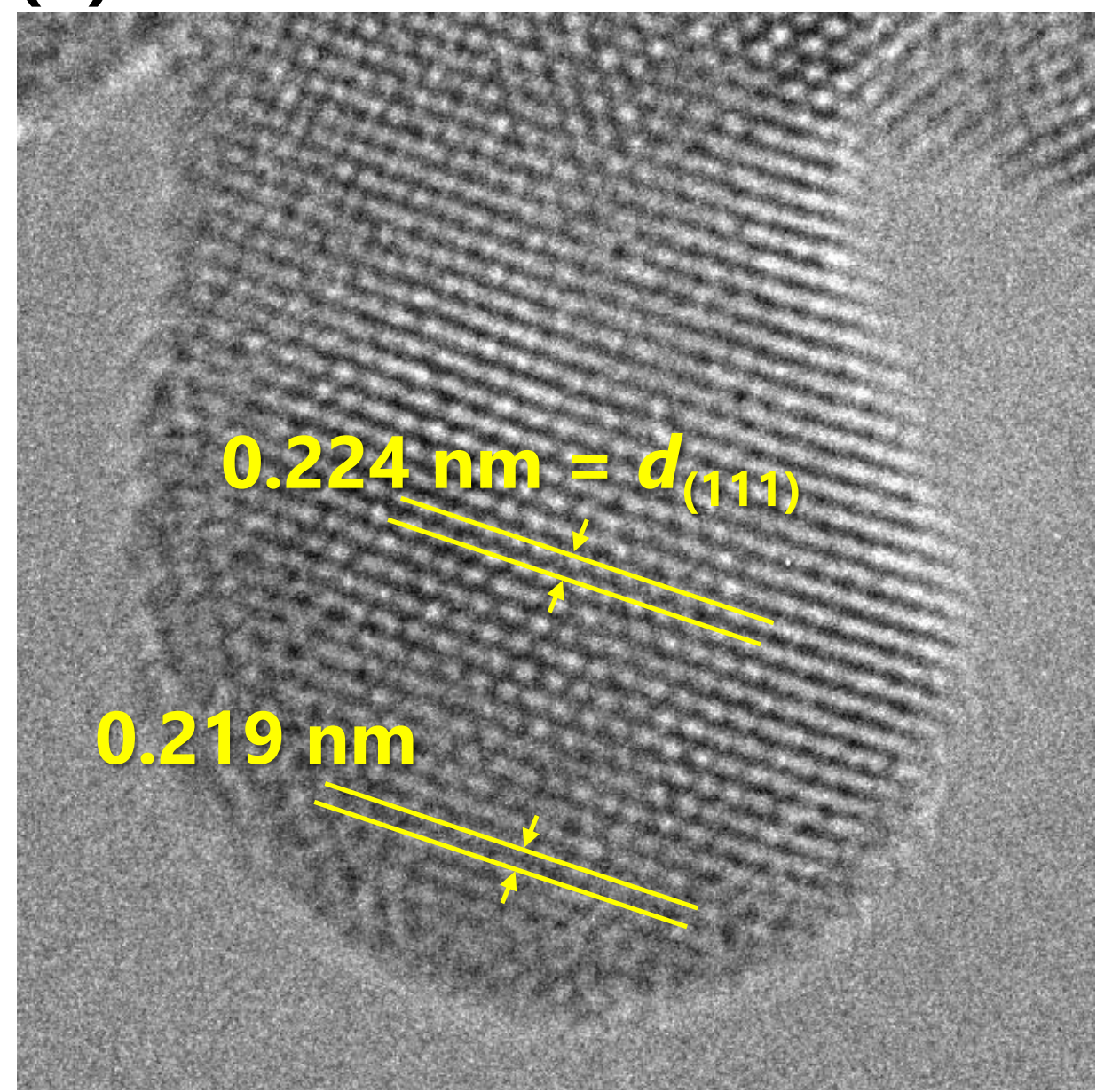


(a)

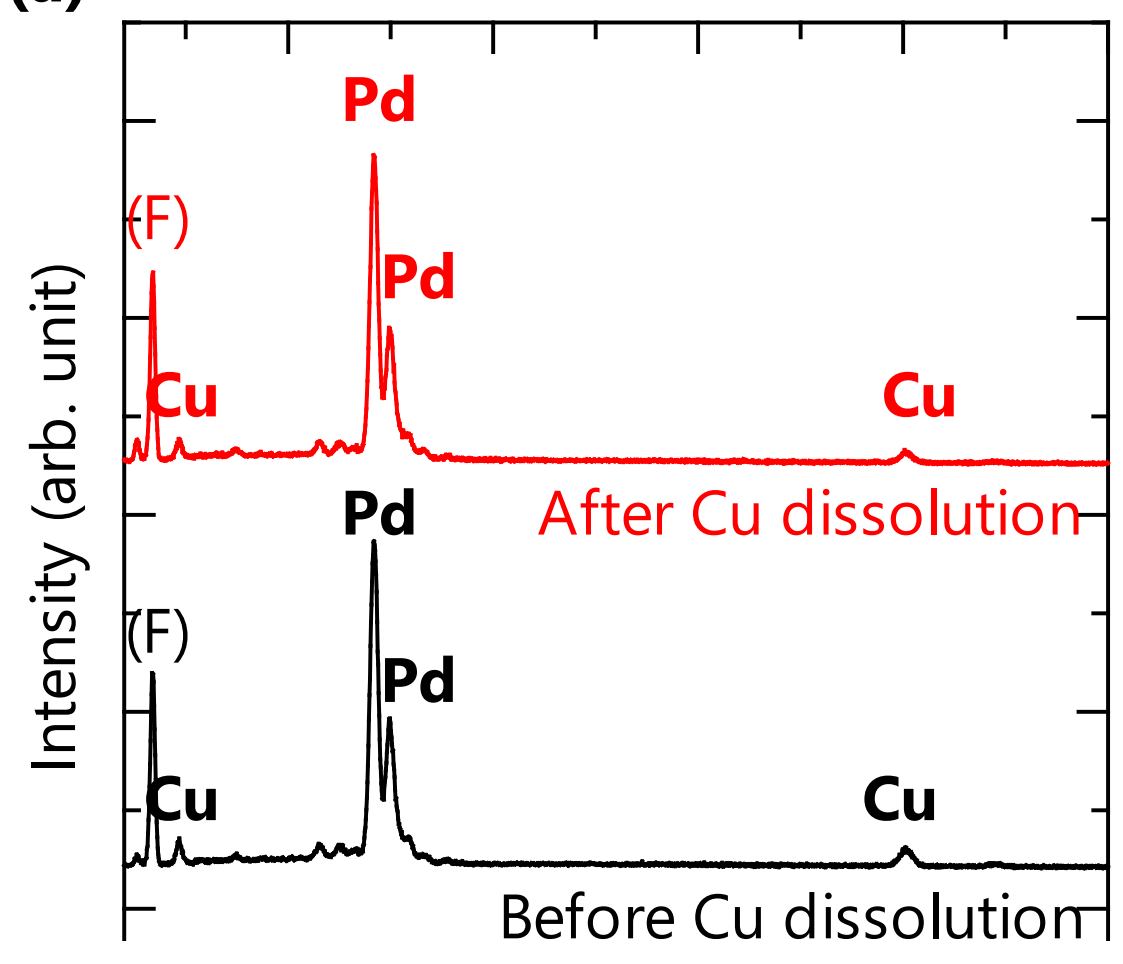

(b)

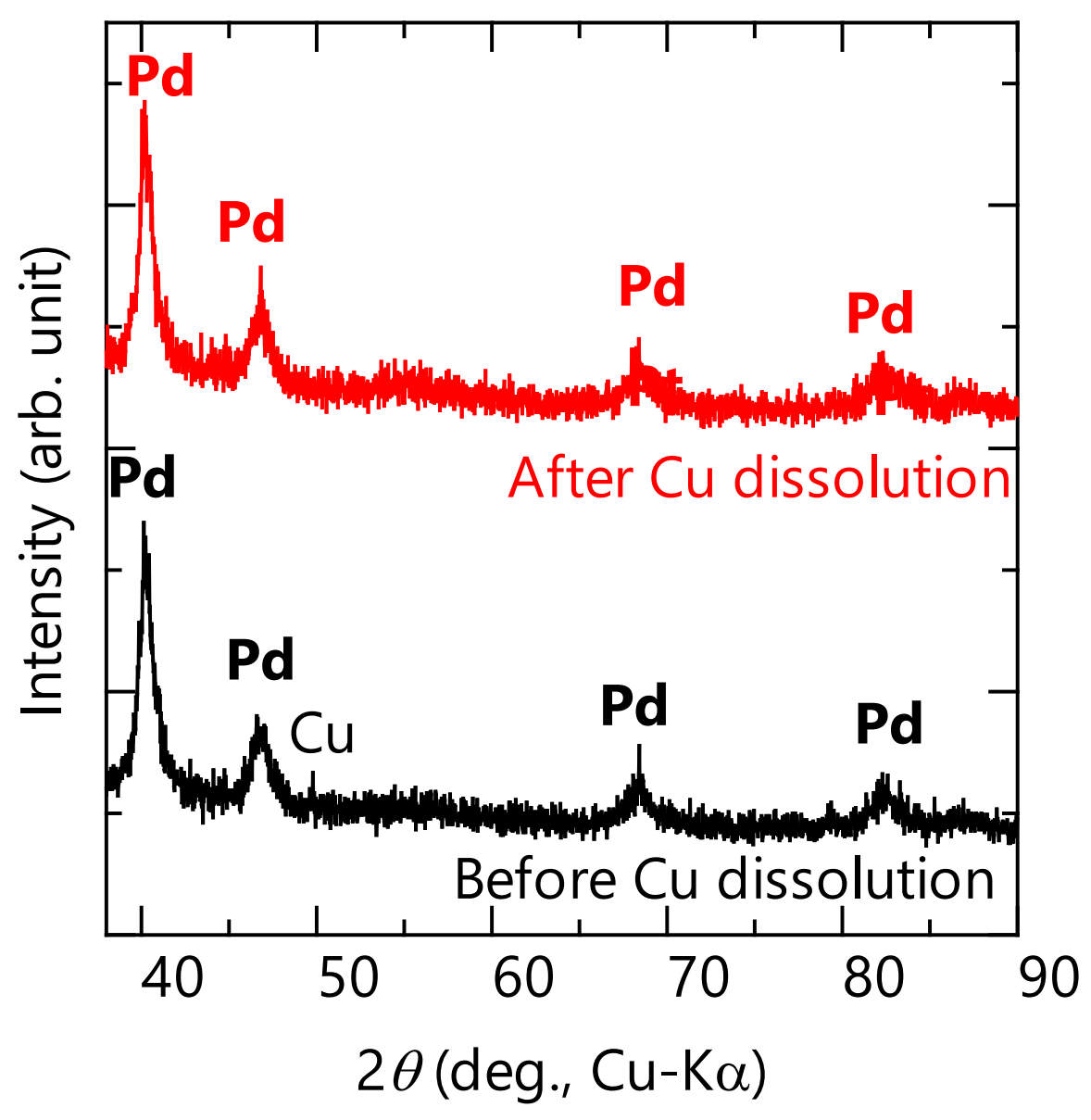


(a)

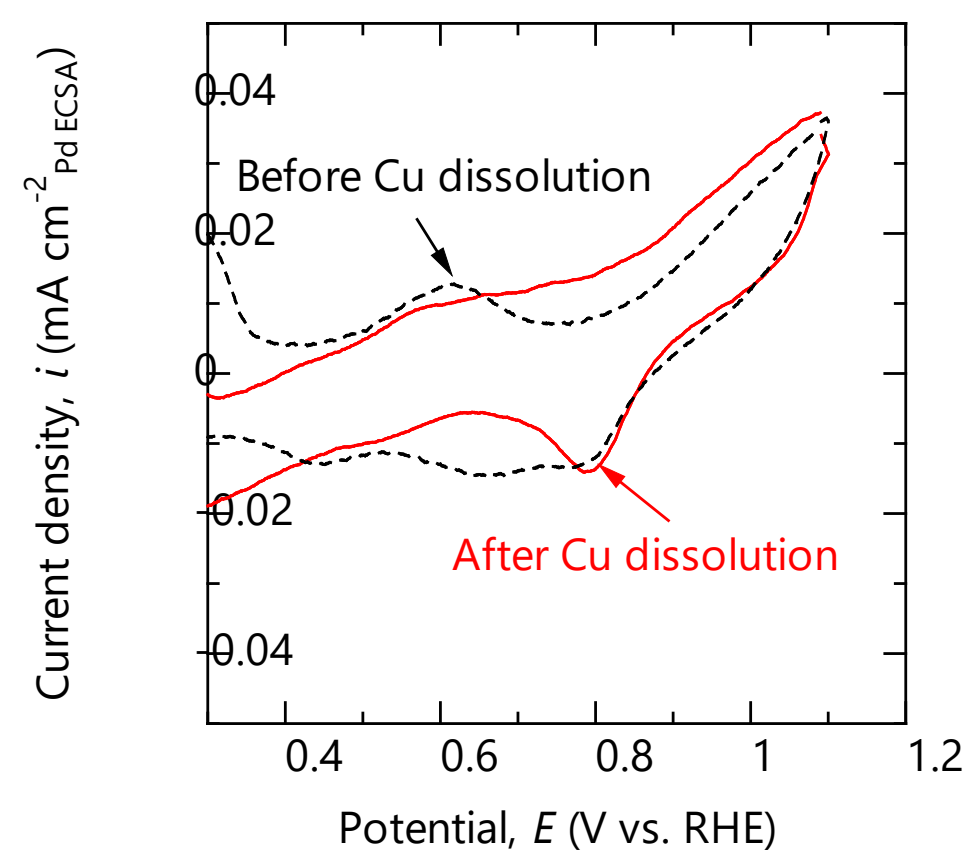

(b)

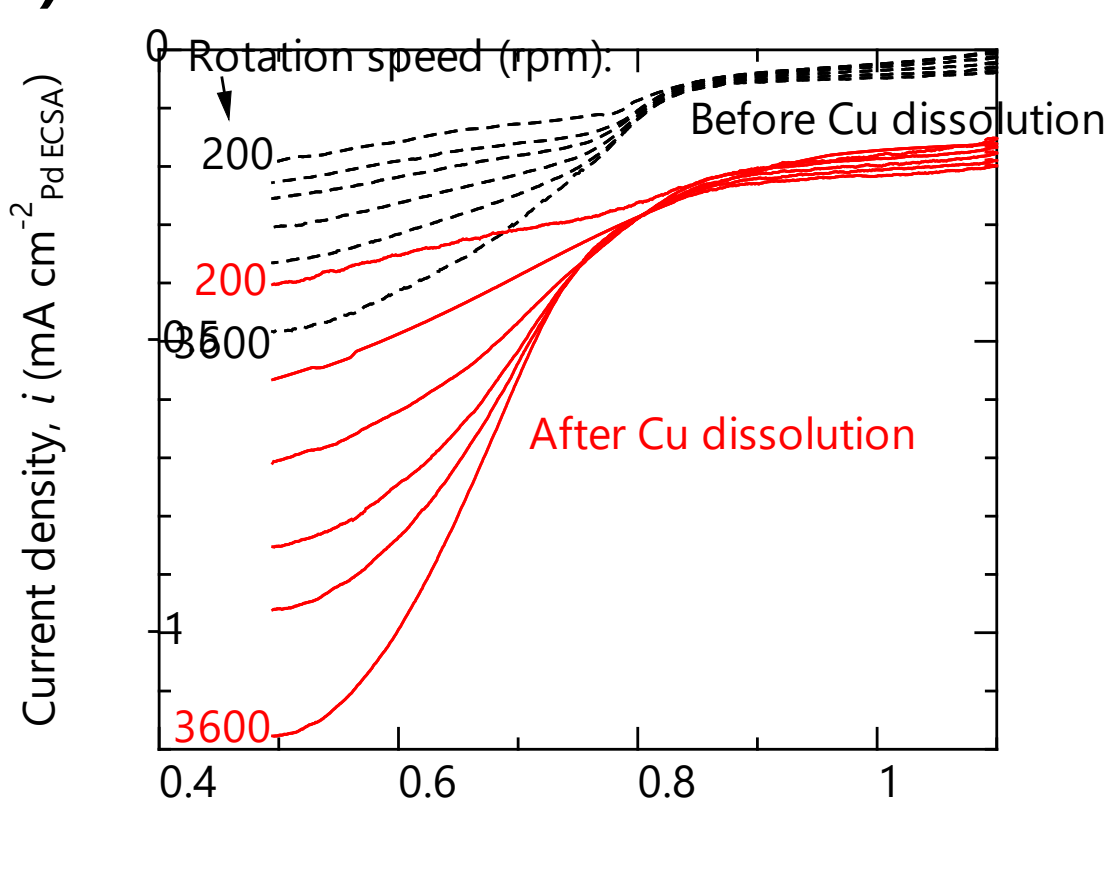



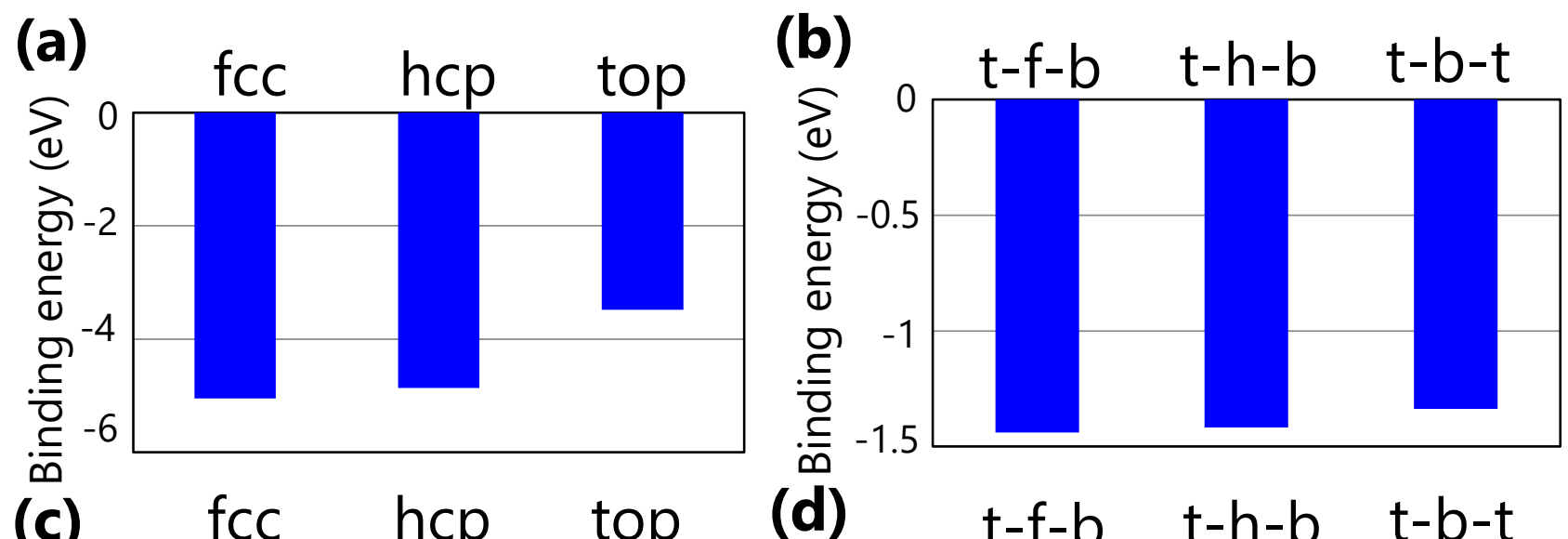

(c) fcc hcp top

(d) $\quad t-f-b \quad t-h-b \quad t-b-t$
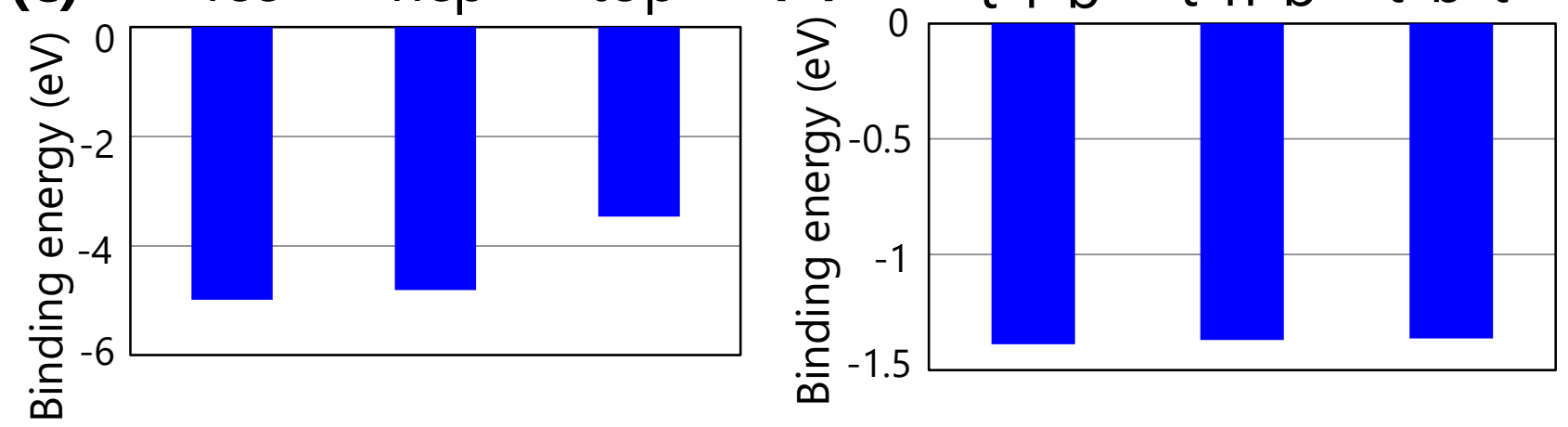

(e)

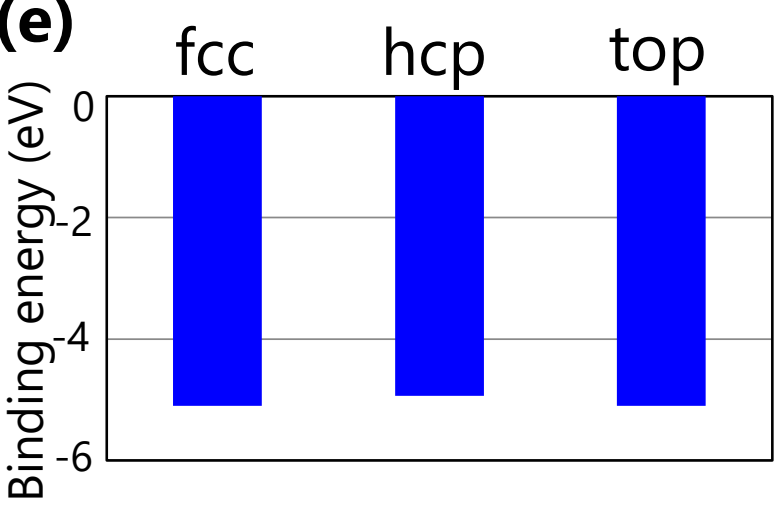

(f)

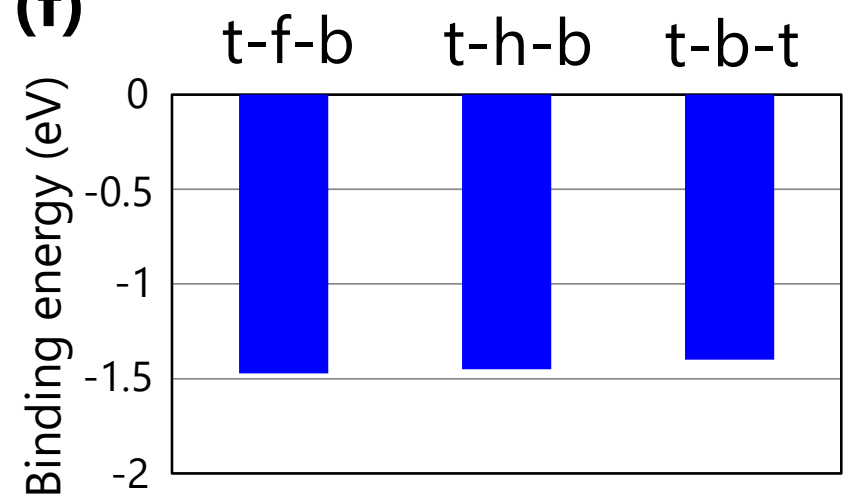


0

(a) $\mathrm{fcc} 1 \mathrm{fcc} 3$ top1 top3 hcp1 hcp3

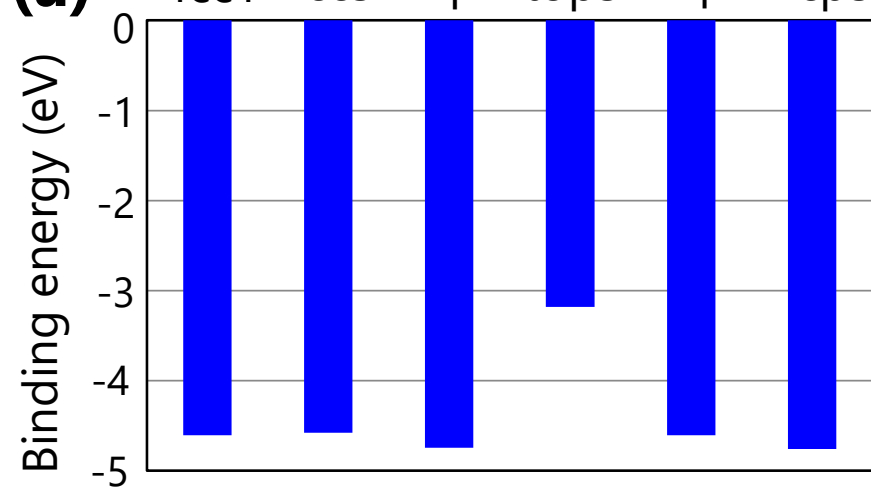

(c) fcc1 fcc3 top1 top3 hcp1 hcp3

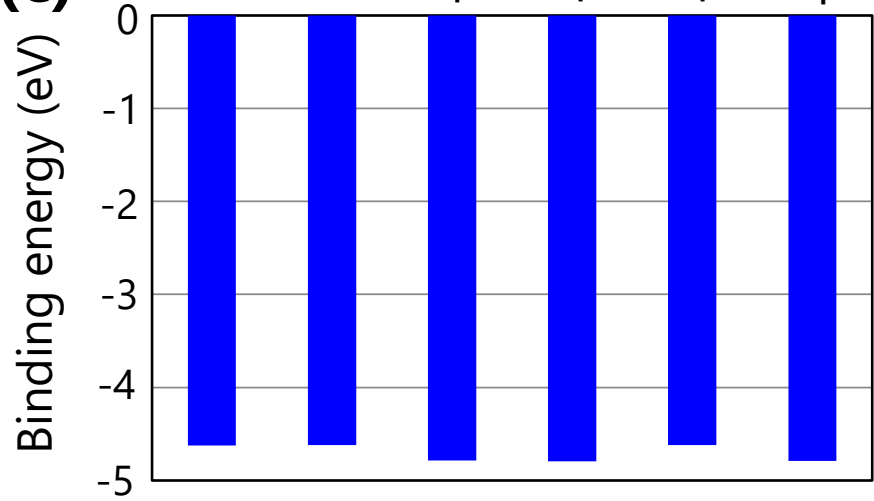

(e) fcc1 fcc3 top1 top3 hcp1 hcp3

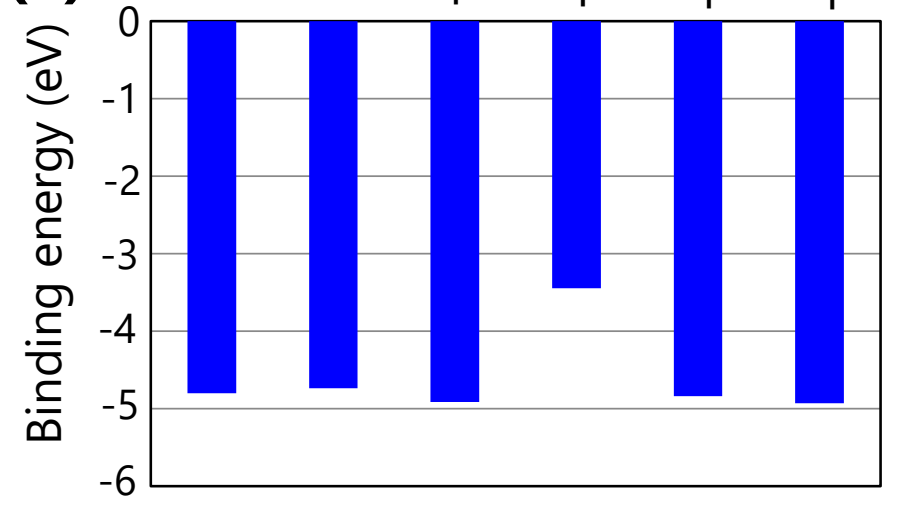

$\mathrm{O}_{2}$

(b) t-b-ta t-b-tb t-b-tc t-f-bb t-f-bc

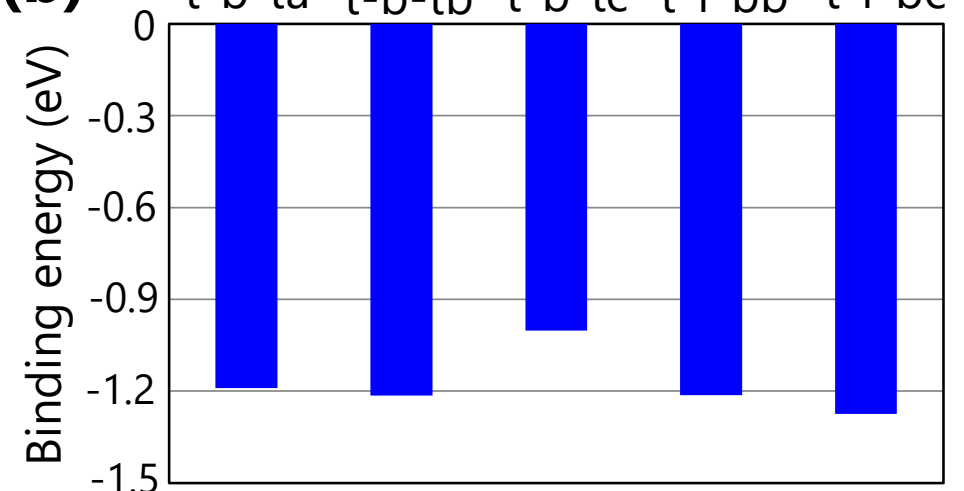

(d) t-b-ta t-b-tb t-b-tc t-f-bb t-f-bc

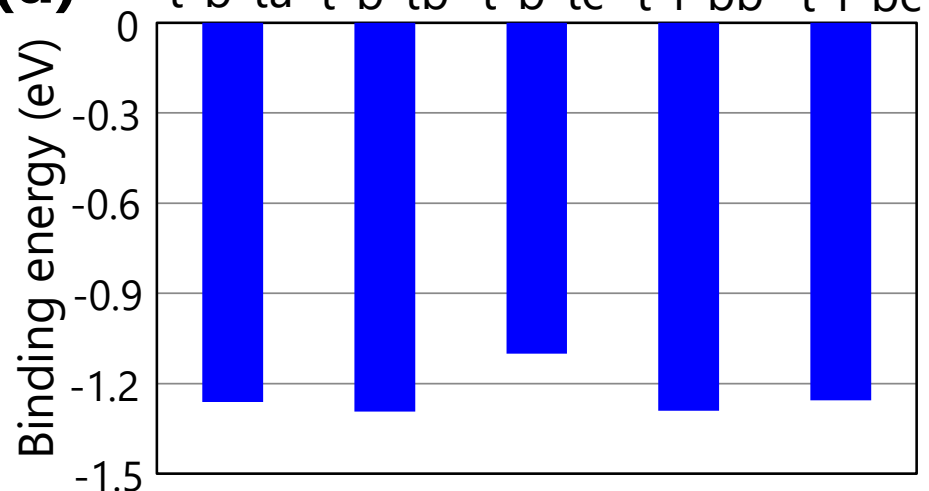

(f) t-b-ta t-b-tb t-b-tc t-f-bb t-f-bc

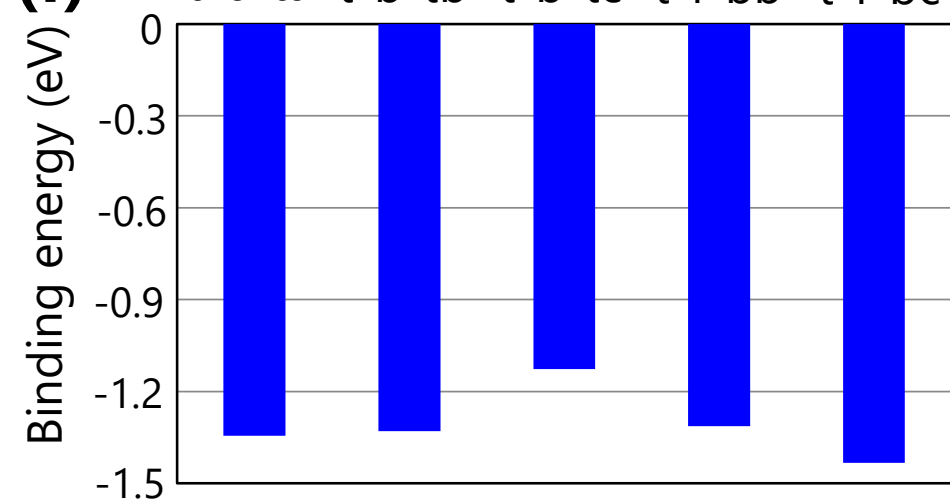


Charge map

Skin $(0 \%, \mathrm{fcc})$

(a)

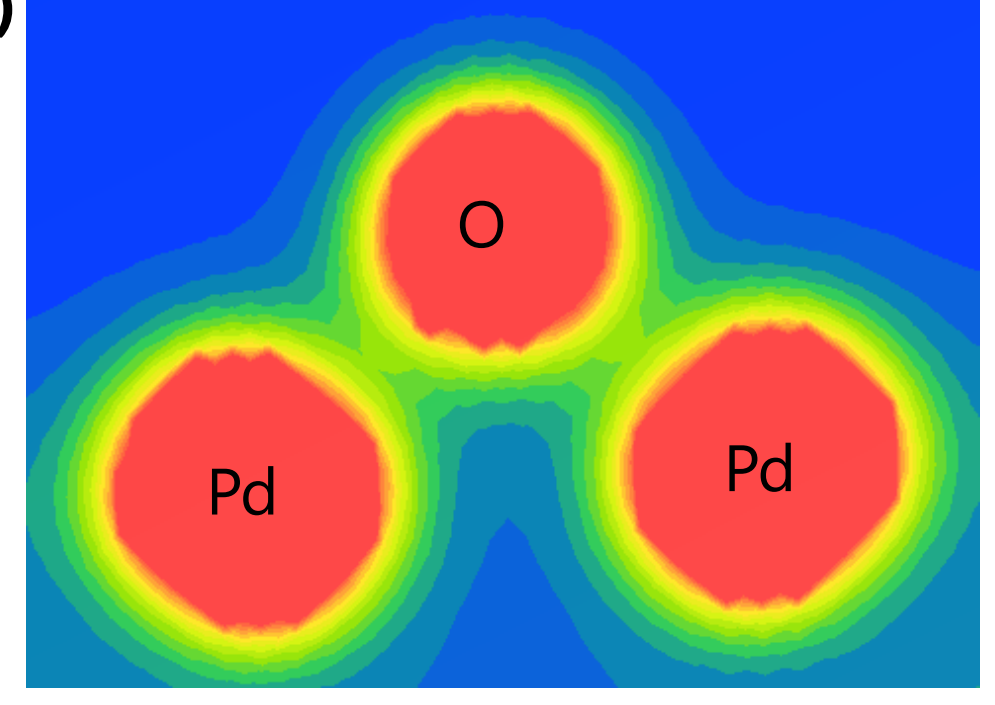

Skin $(-2 \%, f c c)$

(b)

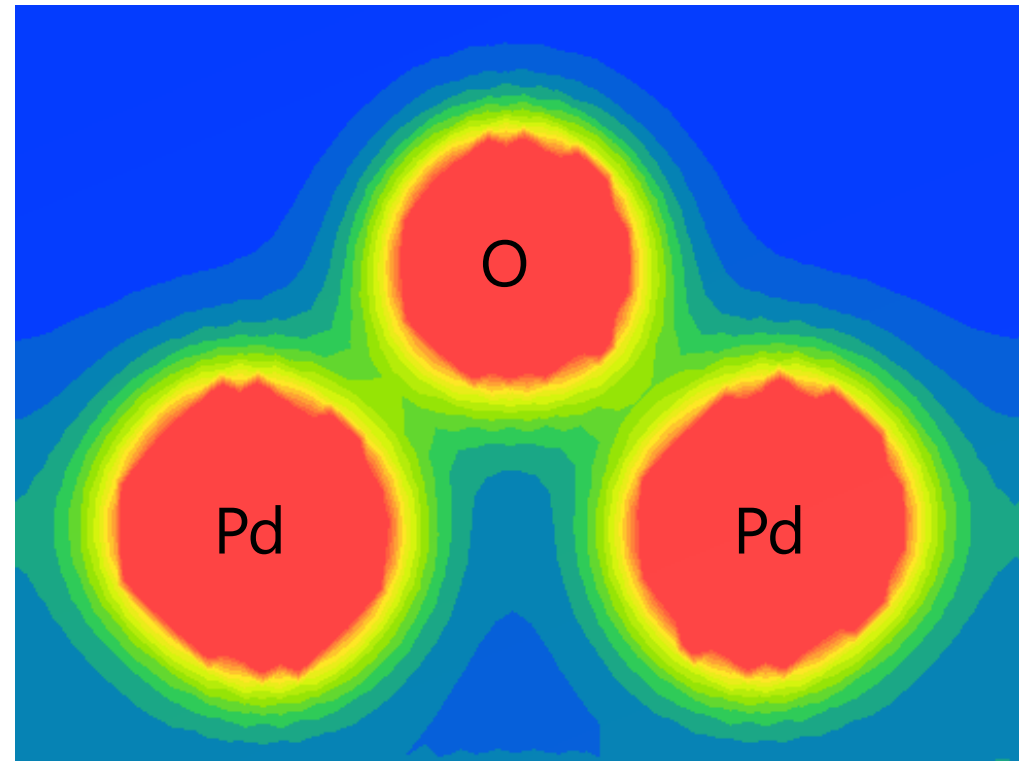

$\mathrm{PdCu}(0 \%$, top 1$) \quad$ (c)

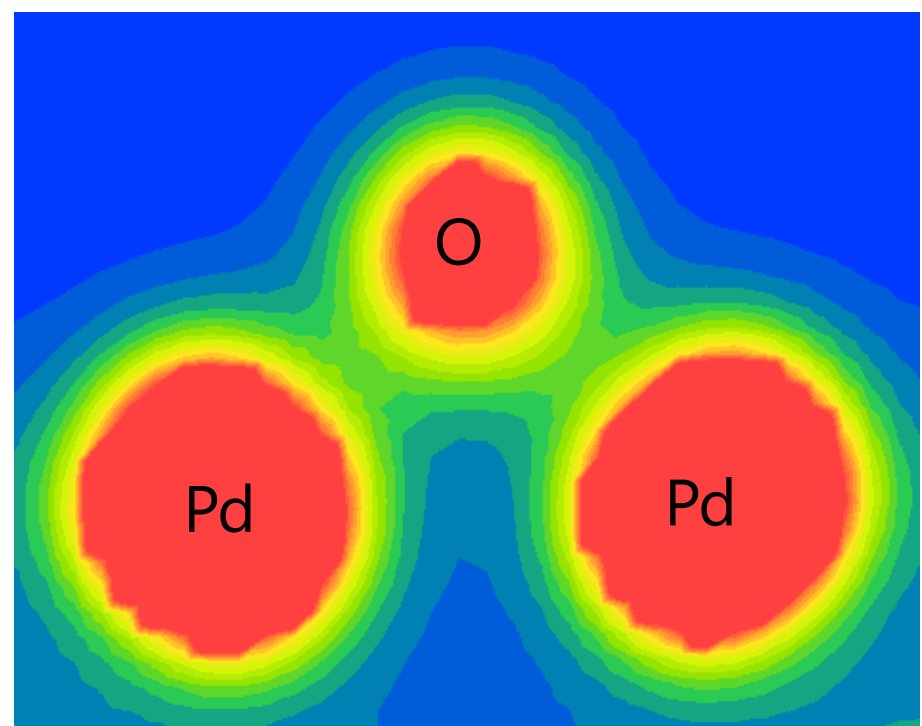

electrons

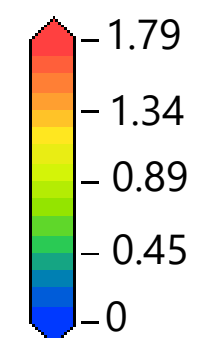


(a)
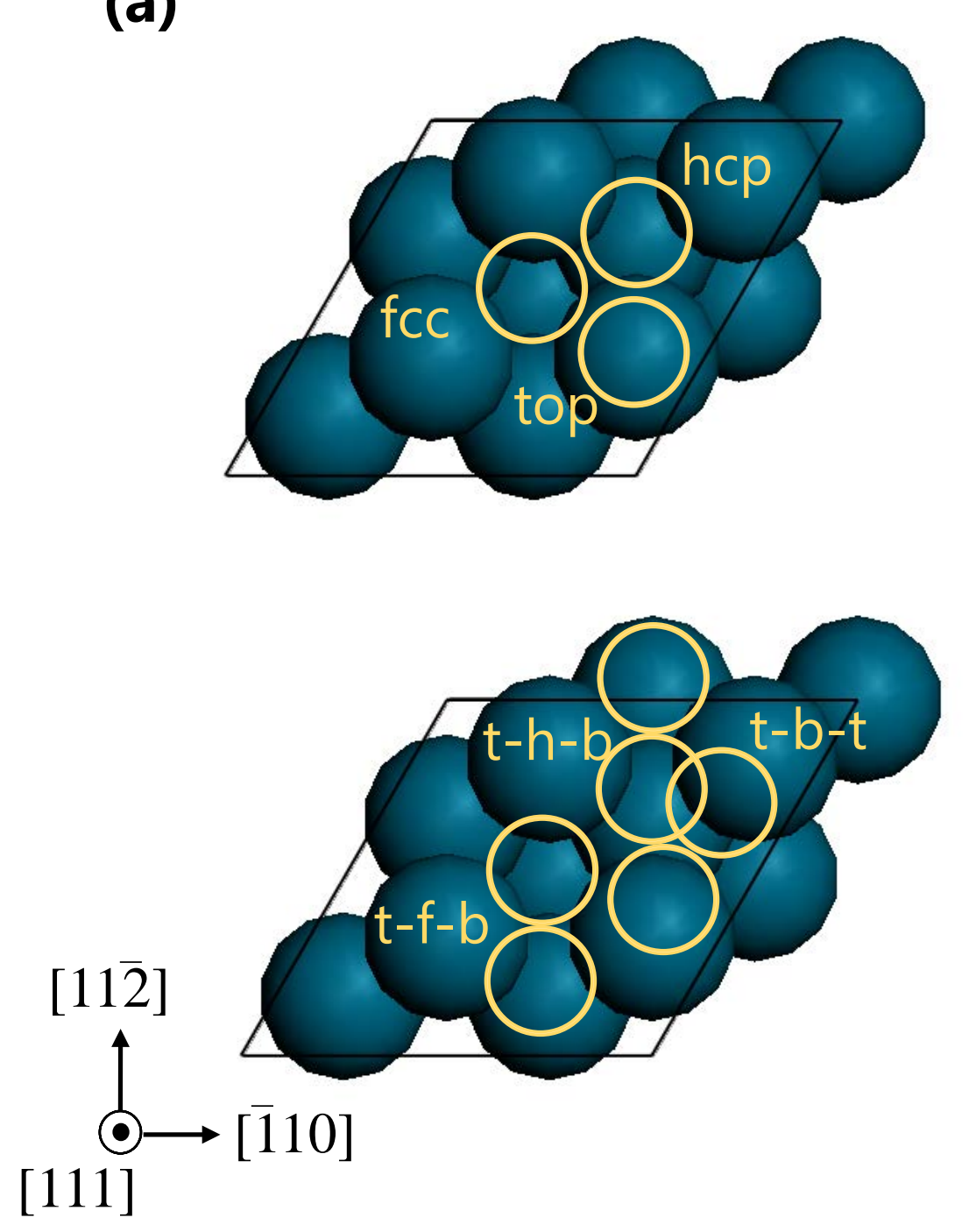

(b)
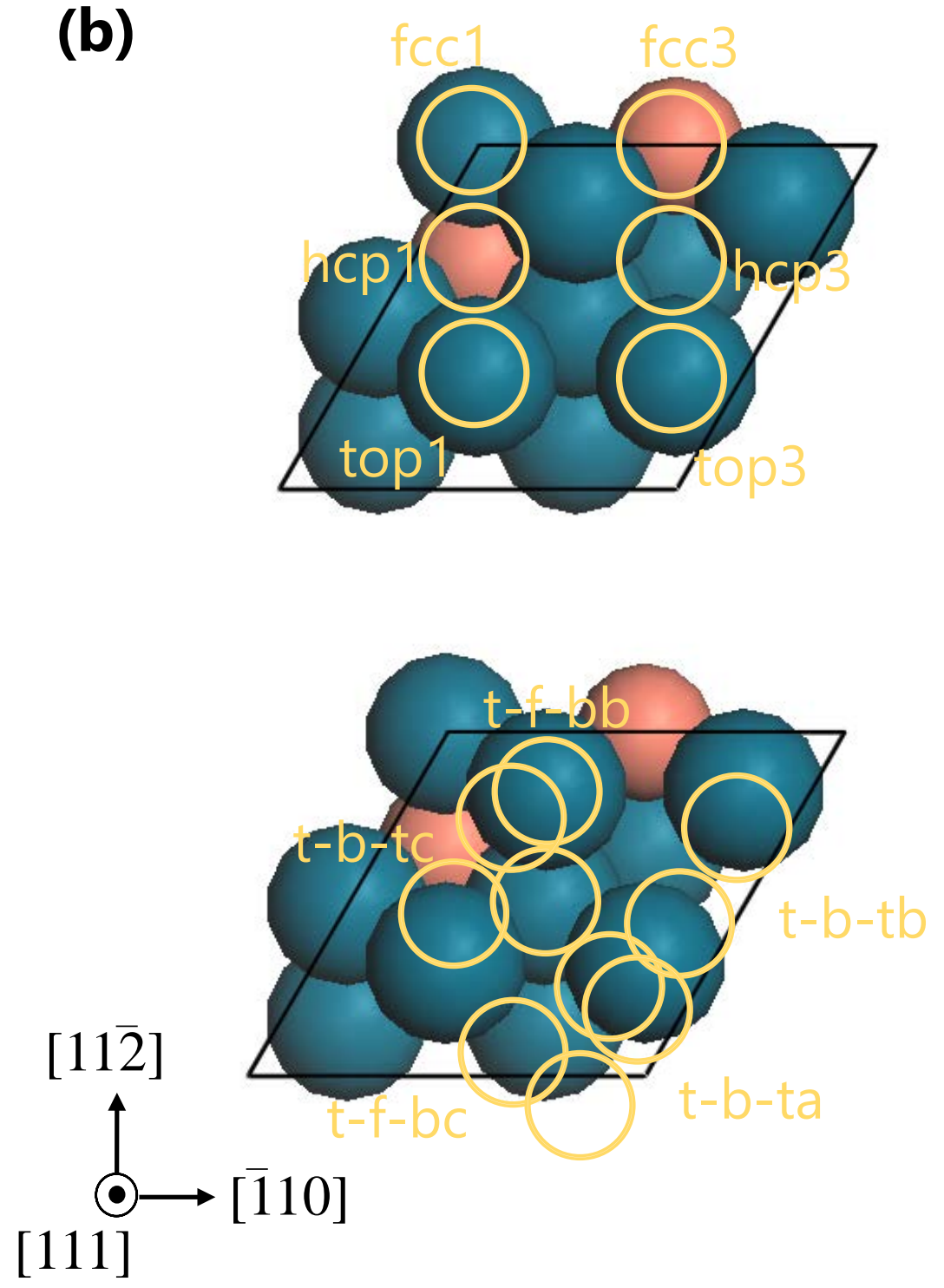

Figure S1 
skin

\section{(a) $0 \%(f c c)$}

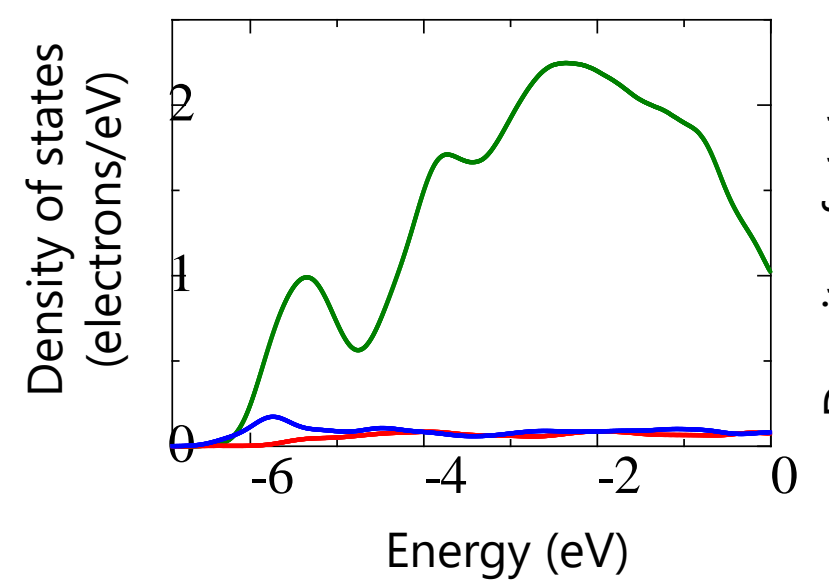

$\mathrm{Cu}$

\section{(d) $0 \%$ (top1)}

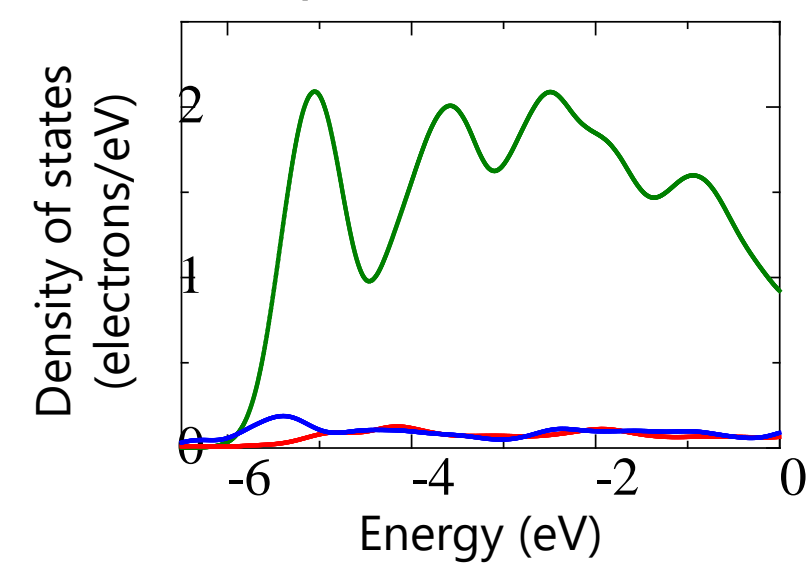

(b) $-2 \%(f c c)$

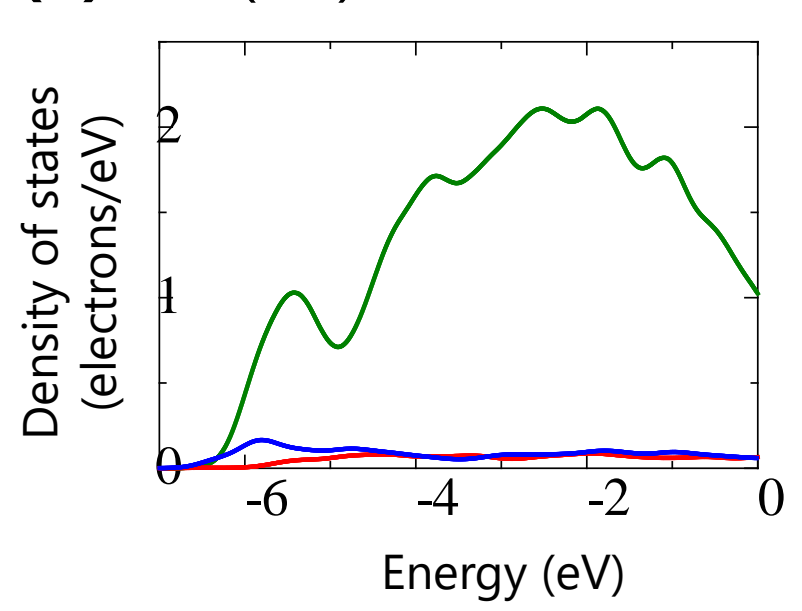

(e) $-2 \%$ (top3)

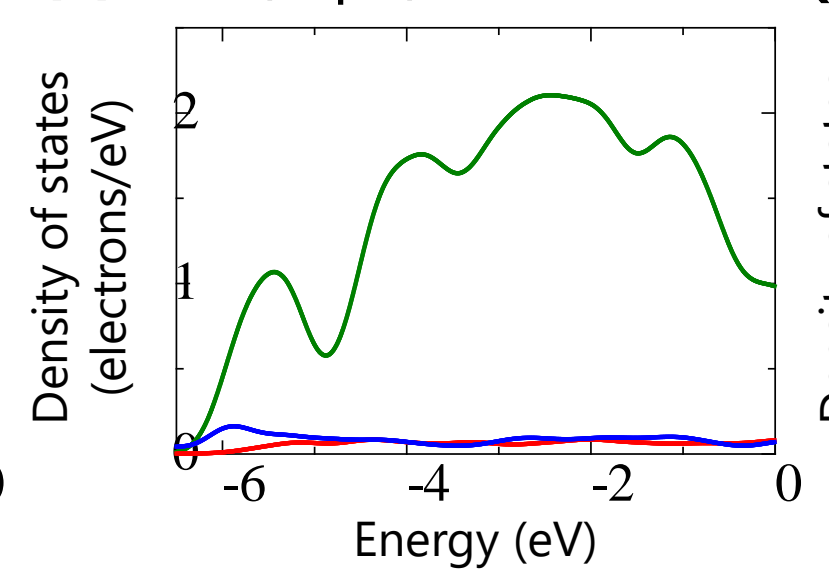

(c) $+2 \%(f c c)$

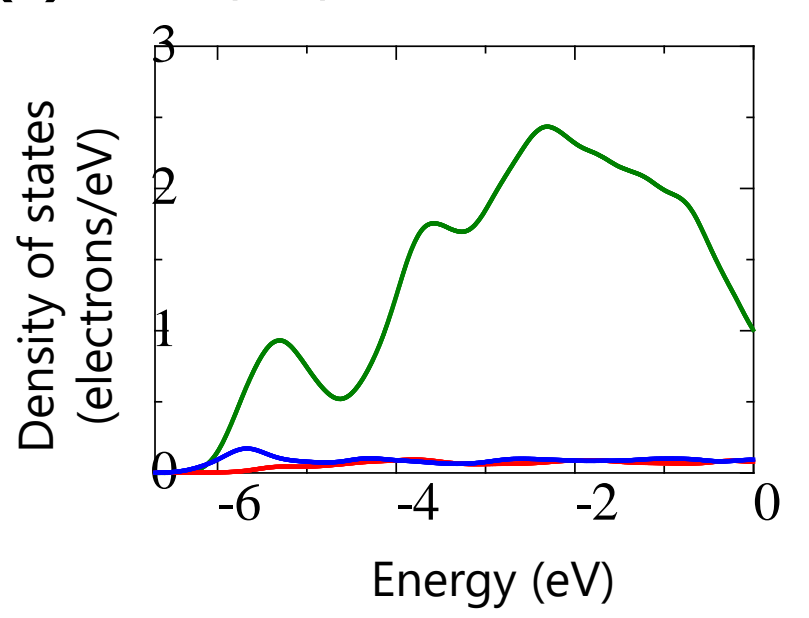

(f) $+2 \%(\mathrm{hcp} 3)$

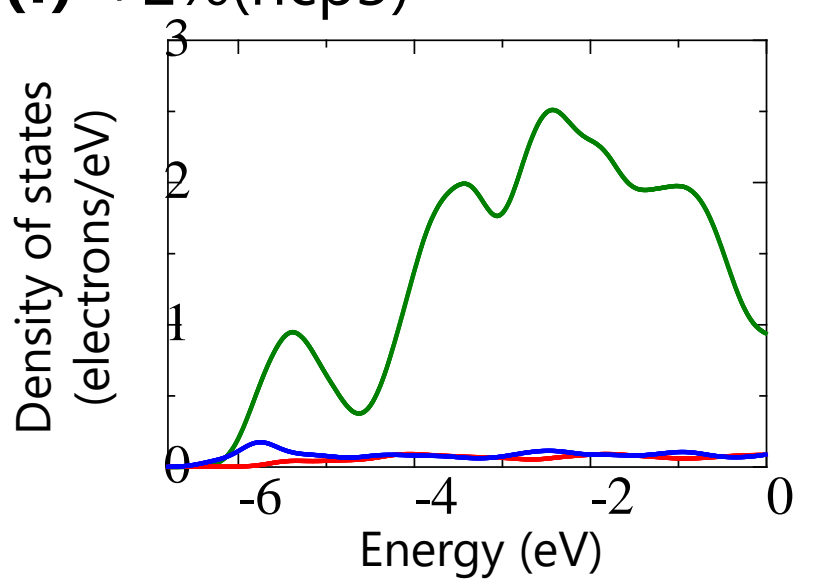

Figure S2 


\section{Supplemental Information for:}

\section{Oxygen reduction on bimodal nanoporous palladium-copper catalyst} synthesized using sacrificial nanoporous copper

Naoki Miyazawa, Masataka Hakamada*, Yuto Sato and Mamoru Mabuchi

Department of Energy Science and Technology, Graduate School of Energy Science, Kyoto University, Yoshidahonmachi, Sakyo, 606-8501 Kyoto, Japan

* Corresponding author. E-mail: hakamada.masataka.3x@kyoto-u.ac.jp (M. Hakamada). 
skin

(a) $0 \%$ (fcc)

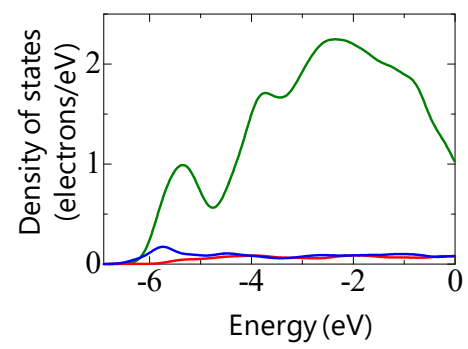

$\mathrm{Cu}$

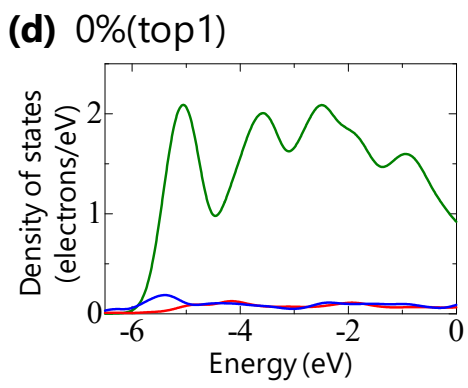

(b) $-2 \%(f c c)$

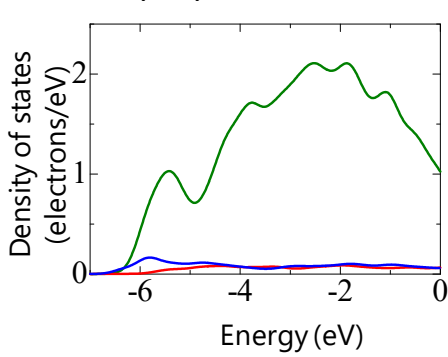

(e) $-2 \%$ (top3)

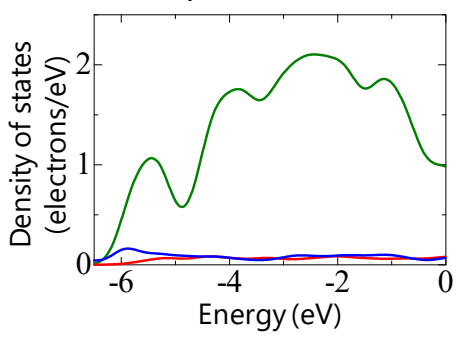

(c) $+2 \%(f c c)$

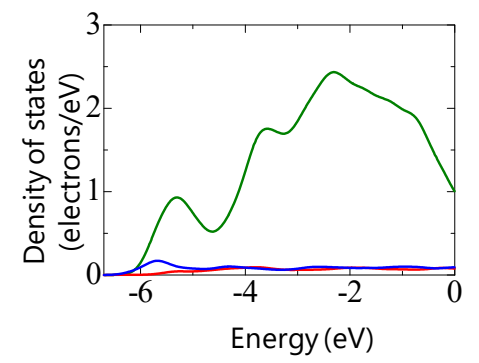

(f) $+2 \%(\mathrm{hcp} 3)$

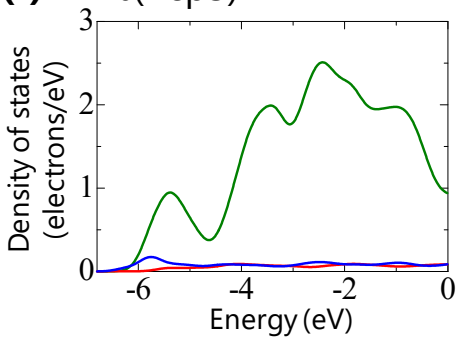

FIG. S1. Densities of states (DOS) for a palladium atom binding to an oxygen atom, (a) Pd surface with $0 \%$ strain, (b) Pd surface with $2 \%$ contraction strain, (c) Pd surface with $2 \%$ expansion strain, (d) Pd-Cu surface with 0\% strain, (e) Pd-Cu surface with 2\% contraction strain and (f) Pd-Cu surface with 2\% expansion strain. 
(a)

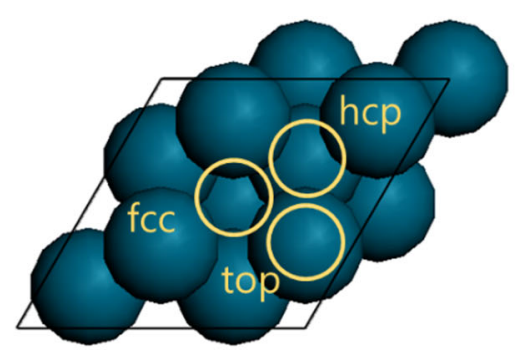

[112]<smiles>CO[Ga]O</smiles>

[111]

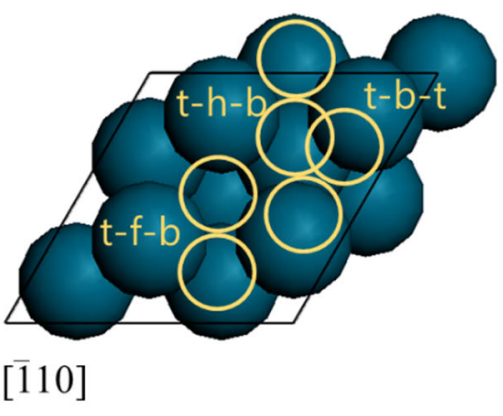

(b)

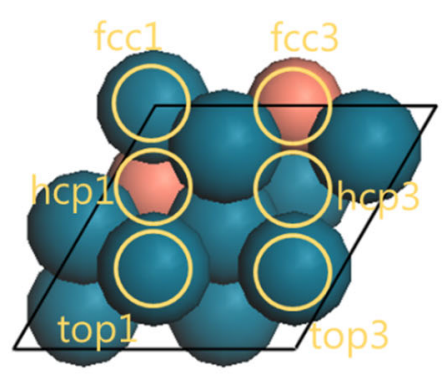

[11]<smiles>CO[AlH2]</smiles>

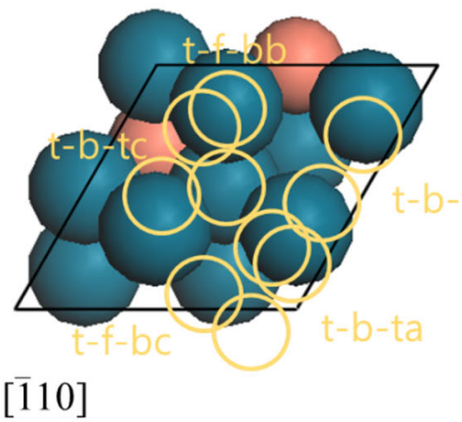

[111]

FIG. S2. Schematic illustration of models used for first-principles calculations, (a) Pd model and (b) Pd-Cu model. The blue and orange balls represent $\mathrm{Pd}$ and $\mathrm{Cu}$ atoms, respectively. The binding sites of $\mathrm{O}$ and $\mathrm{O}_{2}$ species are shown by circles. 